\title{
La configuración de los Colegios Profesionales como entidades de mediación
}

\author{
Irene Araguàs Galcerà \\ Universidad de Barcelona \\ Dpto. de Derecho Administrativo y Procesal
}

SUMARIO

I.- Planteamiento. II.- CONSIDERACIONES GENERALES ACERCA DE LA MEDIACIÓN. 1. El concepto de mediación, sus principios rectores y sus principales ventajas. 2. Mediación natural, mediación profesional y mediación institucional. III.- LA MEDIACIÓN INSTITUCIONAL EN EL MOMENTO PRESENTE. 1. El fomento de la mediación institucional por los poderes públicos. 2. Marco normativo de la mediación institucional en España. A. La regulación estatal. B. La regulación autonómica. IV.- EL PAPEL DE LOS COLEGIOS PROFESIONALES EN EL SENO DE LA MEDIAGIÓN INSTITUCIONAL: SU CONFIGURAGIÓN COMO INSTITUGIONES DE MEDIACIÓN. 1. Una cuestión previa: Colegios Profesionales que tienen la consideración de entidades de mediación. 2. La organización de un servicio público de mediación por parte de los Colegios Profesionales. A. Tipos de mediación que pueden llevar a cabo los Colegios Profesionales. Mediación privada VS. Mediación pública. B. Materias sobre las que pueden mediar los Colegios Profesionales. 3. Las personas mediadoras. Formación y mecanismos de control. A. La formación de las personas mediadoras. B. Mecanismos de control sobre las personas mediadoras. a. Vinculación a una institución de mediación. b. Deberes registrales de los mediadores. c. Responsabilidad civil de los mediadores. d. Régimen sancionador de los mediadores. e. Códigos de conducta de los mediadores. 4. El procedimiento de mediación y el acuerdo de mediación. A. La solicitud de mediación y la designación de mediador. B. El desarrollo de la mediación. C. La terminación de la mediación. D. La retribución del mediador. E. El acuerdo de mediación. 5. Funciones relacionadas con el desarrollo e impulso de la mediación institucional. V.- CONSIDERACIONES FINALES 


\section{PALABRAS CLAVE:}

Colegios Profesionales, mediación, formación mediadores.

\section{RESUMEN:}

De conformidad con la última Ley estatal de mediación en materia civil y mercantil, los Colegios Profesionales han adquirido la condición de entidades de mediación.

La mediación es un sistema alternativo de resolución de conflictos que, en relación a la vía judicial, presenta numerosos beneficios, entre los que se encuentran un menor coste, la rapidez o un mayor cumplimiento de los acuerdos adoptados. Estas ventajas que plantea la mediación han provocado un aumento significativo de las personas que acuden a la mediación, así como de las normas que la regulan. Entre los aspectos más importantes de esta nueva regulación, se encuentra la preparación y formación de los mediadores. Además, la nueva normativa también persigue el fomento y desarrollo de la mediación, lo cual es posible gracias a la colaboración de diferentes entidades, como los Colegios Profesionales.

En este trabajo, intentaremos clarificar cuál es el papel de los Colegios Profesionales en el ámbito de la mediación institucional y las reglas que les resultan de aplicación cuando éstos actúan como entidades de mediación.

\section{KEY WORDS:}

Professional Association, mediation, mediator's skill and training.

ABSTRACT:

According to the last Spanish legislation on mediation in civil and mercantile affairs, Professional Associations have become mediation institutions.

Mediation is a form of alternative dispute resolution (ADR) that includes a lot of benefits, like cheapness, quickness or compliance. The strengths of mediation have resulted in a significant improvement in the use of mediation and in the regulations on mediation. One of the most important aspects in the new mediation's legal framework is focused on the mediator's skill and training. These regulations also try to promote and develop mediation, which is possible thanks to the collaboration of different entities, like Professional Associations.

In this paper we will try to clarify which is the role of the Professional Associations about mediation and which are the rules that have to be applied when they act like a mediation institution. 


\section{PLANTEAMIENTO ${ }^{1}$}

El régimen jurídico de los Colegios Profesionales en España viene conformado, esencialmente, por los preceptos que les dedica nuestra Carta Magna ${ }^{2}$; por la Ley 2/1974, de 13 de febrero, de Colegios Profesionales (en adelante LCP), de carácter básico en muchos de sus preceptos ${ }^{3}$; así como por la legislación autonómica de desarrollo, que se ha plasmado en las diversas leyes sobre Colegios Profesionales que han dictado todas las Comunidades Autónomas, con la única excepción de Asturias ${ }^{4}$.

Esta regulación ha sido objeto de diversas modificaciones, que han afectado, sobretodo, a la LCP, norma que en breve se verá derogada definitivamente por la entrada en vigor de la Ley de Servicios Profesionales estatal ${ }^{5}$. La última de las

${ }^{1}$ Este trabajo se ha realizado en el marco del Proyecto de Investigación DER 2012-32130 "Público y privado en la ordenación y prestación de actividades y servicios: intereses generales, derechos sociales y libertades económicas", concedido por el Ministerio de Educación de España.

${ }^{2}$ Así, el art. 36 CE dispone: "La ley regulará las peculiaridades propias del régimen jurídico de los Colegios Profesionales y el ejercicio de las profesiones tituladas. La estructura interna y el funcionamiento de los Colegios deberán ser democráticos".

Además de este precepto, también inciden, aunque de manera más indirecta, en la configuración y régimen jurídico de los Colegios Profesionales los artículos 22 CE (libertad de asociación); 139 CE (libre circulación y establecimiento de personas en todo el territorio español); 149.1 CE apartados 18 y 30 (bases del régimen jurídico de las Administraciones Públicas y del Procedimiento Administrativo Común; y requisitos de las profesiones tituladas, respectivamente).

${ }^{3} \mathrm{Al}$ tratarse de una norma preconstitucional, debe "inferirse" cuáles son los preceptos básicos, tarea que resulta posible gracias a los diversos pronunciamientos del Tribunal Constitucional en este ámbito, entre los que pueden destacarse las siguientes sentencias: STC 89/1989, de 11de mayo; STC 113/1994, de 25 de abril; STC 179/1994, de 16 de junio; y, más recientemente, la STC 3/2013, de 17 de enero.

${ }^{4}$ Así, en materia de Colegios Profesionales, a nivel autonómico se han dictado las siguientes normas: Ley del País Vasco 18/1997, de 21 de noviembre, de ejercicio de profesiones tituladas y de colegios y consejos profesionales; Ley 6/1997, de 4 de diciembre, de Consejos y Colegios Profesionales de la Comunidad Valenciana; Ley 8/1997, de 8 de julio, de Colegios Profesionales de Castilla y León; Ley foral 3/1998, de 6 de abril, de Colegios Profesionales de Navarra; Ley 10/1998, de 14 de diciembre, de Colegios Profesionales de las Illes Balears; Ley 4/1999, de 31 de marzo, de Colegios Profesionales de La Rioja; Ley 10/1999, de 26 de mayo, de creación de Colegios Profesionales de Castilla y la Mancha; Ley 6/1999, de 4 de noviembre, de Colegios Profesionales de la región de Murcia; Ley 1/2001, de 16 de marzo, de Colegios Profesionales de Cantabria; Ley 11/2001, de 18 de septiembre, de colegios profesionales de la Comunidad Autónoma de Galicia; Ley 31/1998, de 6 de abril; Ley catalana 7/2006, de 31 de mayo, del ejercicio de las profesiones tituladas y de los Colegios Profesionales.

${ }^{5}$ En la fecha de cierre de redacción de este trabajo, la tramitación de la Ley de Servicios Profesionales se encontraba en fase de anteproyecto, aprobado por el Consejo de Ministros el 2de agosto de 2013, y habiendo finalizado el período de enmiendas el 16 de septiembre de 2013. 
modificaciones de la LCP, operada por la Ley 5/2012, de 6 de julio, de mediación en asuntos civiles y mercantiles (en adelante Ley 5/2012), ha tenido por objeto incorporar entre las finalidades de los Colegios Profesionales "el impulso y desarrollo de la mediación”, añadiendo una letra ñ) al art. 5 LCP. Ello, junto con las demás previsiones de la Ley 5/2012 y de las diversas normas autonómicas en materia de mediación, tiene como resultado la configuración de los Colegios Profesionales como entidades de mediación.

Esta última modificación en el régimen jurídico de los Colegios Profesionales llega en un momento especialmente convulso para estas Corporaciones, y es que, pese a la relevancia que les otorga su reconocimiento constitucional, los Colegios Profesionales siempre han estado en el "ojo de huracán" del debate jurídico y político. Mientras que, en un primer momento, dicho debate se centraba en determinar cuál era la naturaleza jurídica de estas corporaciones (cuestión que aún no ha sido zanjada $)^{6}$; en el momento actual, el foco de discusión se centra en la propia configuración legal de los Colegios Profesionales y las funciones que éstos deben (o no deben) realizar.

Los nuevos tintes que ha adquirido el debate relativo a los Colegios Profesionales son consecuencia de la profunda revisión que ha experimentado su regulación a raíz de la aprobación de la Directiva 2006/123/CE del Parlamento Europeo y del Consejo, de 12 de diciembre de 2006, relativa a los servicios en el mercado interior (en adelante Directiva de Servicios) y su transposición al ordenamiento jurídico español ${ }^{7}$, que ha conllevado la modificación de todas aquellas

\footnotetext{
${ }^{6}$ Sobre las distintas posturas doctrinales acerca de la naturaleza jurídica de los Colegios Profesionales, véase: Baena de Alcázar, M. Los Colegios Profesionales en el Derecho Administrativo Español, Ed. Montecorvo, Madrid, 1968; Calvo Sánchez, L. Régimen jurídico de los Colegios Profesionales, Ed. Civitas, Madrid, 2000; AAVV (Coord. Martín-Retortillo, L.), Los Colegios Profesionales a la luz de la Constitución, Ed. Civitas, Madrid, 1996; Martínez López-Muñiz, J.L., "Naturaleza de las Corporaciones Públicas Profesionales", Revista Española de la Administración Pública, Civitas, núm. 39, 1983; Salom Parets, A., Los Colegios Profesionales, Ed. Atelier, Barcelona, 2007.

${ }^{7}$ Sobre la transposición de la Directiva Servicios, hay abundante literatura jurídica. Sin ánimo de exhaustividad, podemos hacer referencia a las siguientes obras: AA.VV. Retos y oportunidades para la transposición de la Directiva de Servicios, 2009, 25 edición del Libro Marrón, Círculo de Empresarios, Madrid; AA.VV., "El impacto de la Directiva Bolkestein y la reforma de los servicios en el Derecho Administrativo" (Dir. E. Moreu Carbonell), Monografías de la Revista Aragonesa de Administración Pública, Zaragoza, 2010; AA.VV., Retos de la Directiva de Servicios, Revista Catalana de Dret Públic nº42, in totum (Dir. B. NoGUERA y S. SARTORIO), 2010; AAVV. El impacto de la Directiva de Servicios en las Administraciones Públicas: aspectos generales y sectoriales (Dir. Aguado i Cudolà, V. y Noguera de la Muela, B.), Atelier, 2012; AAVV. La termita Bolkestein (Dir. A. Nogueira), Dykinson, 2012; De la Cuadra Salcedo Janini, T. "¿Quo Vadis, Bolkestein? ¿Armonización o desregulación?", Revista Española de Derecho Europeo n²2, Madrid, 2007; De la Cuadra Salcedo, T. El mercado interior de servicios en la Unión Europea. Estudios sobre la Directiva
} 
normas legales (estatales y autonómicas) así como reglamentarias que contradijeran sus previsiones.

A nivel estatal, como todos sabemos, la transposición de la Directiva Servicios se ha llevado a cabo, fundamentalmente, a través de dos normas: la Ley 17/2009, de 23 de noviembre, de libre acceso a las actividades de servicios y su ejercicio (Ley Paraguas) y la Ley 25/2009, de 22 de diciembre, de modificación de diversas leyes para su adaptación a la ley sobre el libre acceso a las actividades de servicios y su ejercicio (Ley Ómnibus).

En el ámbito autonómico, el proceso de transposición de la Directiva Servicios ha seguido cauces distintos según la Comunidad Autónoma. Mientras que ha habido Comunidades que han optado por modificar cada una de las leyes sectoriales afectadas por la Directiva Servicios, otras han preferido dictar una "Ley Ómnibus autonómica"8.

123/2006/CE relativa a los servicios en el mercado interior. Ed. Marcial Pons, Madrid, 2009; FuerTes LóPEZ, M., "Luces y sombras en la incorporación de la Directiva de Servicios", RCDP n42, pp. 57-83, 2011; García López, P.A., "Transposición de la Directiva de Servicios en el caso de España”, Partida Doble núm. 195, 2008; GonzÁlez García, J., "La transposición de la Directiva de Servicios: Aspectos normativos y organizativos en el Derecho español", Revista Española de Derecho Europeo, núm. 32, 2009: LAGUNA DE PAZ, J.C., "La Directiva de Servicios: El estruendo del parto de los montes", El Cronista del Estado Social y Democrático de Derecho, núm. 6, 2009: Martínez López-MuñIz, J.L., "Naturaleza de las Corporaciones Públicas Profesionales", Revista Española de la Administración Pública, Givitas, núm. 39, 1983; MuÑoz Machado, S. y Fernández, T.R. (2008). "La Directiva Bolkestein: Liberalización al servicio del consumidor", Asociación para el Progreso de la Dirección, núm. 231, 2008; Parejo Alfonso, L., "La desregulación de los servicios con motivo de la Directiva Bolkestein: La interiorización, con paraguas y en ómnibus de su impacto en nuestro sistema". El cronista del Estado Social y Democrático de Derecho, junio 2009; Rivero OrTeGa, R. (Dir.), Mercado Europeo y reformas administrativas. La transposición de la Directiva de Servicios en España, Civitas-Thomson Reuters, Cizur Menor, 2009; Rivero OrtegA, R., "Antecedentes, principios generales y repercusiones administrativas de la Directiva de Servicios: Problemas de su transposición en España”, Revista de Estudios Locales, número monográfico, 2009; Villarejo Gallende, H., Salvador Armendáriz, M.A. "El complejo proceso de transposición de la Directiva de Servicios", en Informe de Comunidades Autónomas 2008, vol. I, Ed. Instituto de Derecho Público, Barcelona, 2009.

Asimismo, también en el Derecho comparado podemos encontrar obras sobre la materia. Al respecto, pueden verse: D'Agunto, S., "Directive Services (2006/123/CE): radiographie juridique en dix points", Revue du droit de l'Union Européenne n'2; PELOW, K, "La libre prestation de services dans la Directive $\mathrm{n}^{\circ}$ 2006/123/CE", Revue Trimestrielle de Droit Européen, n44, 2008; BarnarD, C., "Unraveling the Services Directive", Common market Law Review, 45, 2008; DAvis G., "The Services Directive: extending the country of origin principle and reforming public administration", European Law Review n 2, 2007.

${ }^{8}$ Entre otras, han dictado leyes ómnibus autonómicas: las Islas Baleares (Ley 12/2010, de 12 de noviembre, de modificación de diversas leyes para la transposición en las Illes Balears de la Directiva 2006/123/CE); o Galicia (Ley 1/2010, de 11 de febrero, de modificación de diversas Leyes de Galicia para su adaptación a la Directiva 2006/123/CE del Parlamento Europeo y del Consejo, de 12 de diciembre de 2006, relativa a los servicios en el mercado interior). En el caso de Cataluña, el proceso de incorpora- 
En relación a la prestación de servicios profesionales, la adaptación al Derecho Europeo provocó la modificación de la LCP y de las diversas normas autonómicas reguladoras de los Colegios Profesionales ${ }^{9}$, lo cual se ha realizado de manera irregular según la Comunidad Autónoma y, con carácter general, de manera poco satisfactoria ${ }^{10}$. Finalmente, también se han tenido que modificar las normas reglamentarias con incidencia en materia de servicios profesionales, esto es, fundamentalmente, los estatutos colegiales ${ }^{11}$.

Todo este entresijo de normas derivadas de la Directiva Servicios ha representado importantes modificaciones en el régimen jurídico de los Colegios Profesionales, hasta el extremo de que los fundamentos sobre los que se asentaban estas Corporaciones han sido replanteados.

Las consideraciones anteriores adquieren nuevos matices a la luz de las previsiones del Anteproyecto de Ley de Servicios Profesionales de 2 de agosto de 2013. El modelo colegial que plantea esta norma, fuertemente criticado por los propios Colegios Profesionales, sitúa a los mismos ante un panorama incierto, siendo cuestionada, incluso, la supervivencia de los mismos, especialmente en relación con los Colegios que van a dejar de ser de colegiación obligatoria, plan-

ción de la Directiva Servicios a la legislación autonómica se ha llevado a cabo a través de tres normas: la Ley 9/2011, de 29 de diciembre, de promoción de la actividad económica; la Ley 10/2011, de 29 de diciembre de simplificación y mejora de la regulación normativa; y la Ley 11/2011, de 29 de diciembre, de reestructuración del sector público para agilizar la actividad administrativa.

${ }^{9}$ Sobre el impacto de la transposición de la Directiva de Servicios en los Colegios Profesionales y las reglas que se derivan de esta nueva regulación: CARLón RuIZ, M., "El impacto de la Transposición de la Directiva de Servicios en el régimen jurídico de los Colegios Profesionales", RAP núm. 183, 2010; DEL SAZ Cordero, S. "La modificación de la Ley estatal 2/1974, de colegios profesionales, como consecuencia de la transposición de la Directiva de servicios", Revista catalana de dret públic, Núm. 42, junio 2011; TRAYTER Jiménez, J.M., "Presente y futuro de los Colegios Profesionales" en Aguado Cudolà, V. y Noguera de LA Muela, B. (Dirs.) (2012): Págs. 191 y siguientes; Vicente Ruiz, Mª', "La reforma de la Ley de Colegios Profesionales impulsada por la Directiva de Servicios", Boletín Económico de Información Comercial Española núm. 2990, 2010, Págs. 51 a 57.

${ }^{10}$ A día de hoy, Comunidades Autónomas como Canarias, Castilla la Mancha, la Comunidad Valencia, Extremadura, Murcia y el País Vasco, mantienen en materia de colegios profesionales sus legislaciones anteriores a la Ley Paraguas, y entre las Comunidades que sí se han adaptado, algunas lo han hecho sólo de forma parcial. En este sentido se pronuncia la Comisión Nacional de la Competencia en el "Informe sobre los Colegios Profesionales tras la transposición de la Directiva Servicios" aprobado en su sesión de 18 de abril de 2012, según el cual únicamente están totalmente adaptadas a la legislación básica Aragón y Cantabria. Pág. 35. El informe se encuentra disponible en: http://www.cncompetencia.es/

${ }^{11} \mathrm{Al}$ respecto, el informe de la Comisión Nacional de la competencia de 18 de abril de 2012 señala la dificultad de extraer unas conclusiones generales, dada la enorme casuística, pero detecta numerosos supuestos en los que los Estatutos Colegiales no se han adaptado correctamente a las previsiones de la Directiva Servicios, ya sea de manera general o en algunos aspectos concretos. 
teándose si los mismos deben ser reconducidos a otras formas jurídicas como las asociaciones profesionales.

Con este telón de fondo, las normas estatales y autonómicas que regulan la mediación institucional siguen una dirección opuesta, atribuyendo a los Colegios Profesionales la condición de instituciones de mediación o entidades mediadoras, y reconociéndoles importantes funciones públicas vinculadas a la implantación y desarrollo de la mediación institucional, cada vez más en auge.

Las cuestiones más importantes que suscita el nuevo estatus de los Colegios Profesionales como instituciones de mediación son objeto de estudio en este trabajo.

\section{GONSIDERACIONES GENERALES ACERGA DE LA ME- DIAGIÓN}

Antes de analizar cuál es el papel de los Colegios Profesionales en el seno de la mediación institucional, resulta necesario realizar una aproximación a ciertos aspectos esenciales de este sistema de resolución de conflictos, que pasa por conocer el propio concepto de mediación, sus principios rectores y principales ventajas; así como los distintos tipos de mediación.

\section{El concepto de mediación, sus principios rectores y sus prin- cipales ventajas}

La mediación es un sistema de resolución de conflictos que tiene dos rasgos que la definen y la dotan de sustantividad propia:

- En primer lugar, la mediación es un sistema de resolución de conflictos autocompositivo. Es decir, en contraposición a los métodos o sistemas heterecompositivos, que son aquellos en que un tercero impone a las partes en conflicto la solución al mismo a través de una resolución (por ejemplo, una resolución judicial o un laudo arbitral); los sistemas autocompositivos se caracterizan porque son las partes quienes alcanzan el acuerdo que pondrá fin a su controversia y, aunque intervenga un tercero, su participación irá a dirigida únicamente a facilitar a el acuerdo de las partes por ellas mismas.

Pese a que los sistemas autocompositivos presentan numerosas ventajas, debemos tener en cuenta que no todos los conflictos pueden resolverse a través de estos métodos. La voluntariedad que subyace a los métodos de resolución de conflictos autocompositivos lleva aparejadas dos limitaciones: la primera de ellas, de derecho, exige que el conflicto a resolver recaiga sobre materias disponibles por las partes; la 
segunda limitación, de hecho, se concreta en que no todos los conflictos, aún versando sobre materias disponibles, reúnen los requisitos o condiciones para poder ser resueltos a través de métodos autocompositivos, pues aunque el punto de partida, obviamente, es un conflicto, es necesario que haya una mínima voluntad de las partes de acercamiento y que las posturas no estén muy enconadas.

- En segundo lugar, la mediación se incardina dentro de los denominados métodos alternativos de resolución de conflictos, conocidos bajo las siglas anglosajonas ADR (Alternative Dispute Resolution), en las que el adjetivo "alternativo" va referido a la opción que representa la mediación, junto con otros sistemas de resolución de conflictos como el arbitraje o la conciliación, frente a la judicialización de los conflictos.

Pese a lo anterior, debemos tener en cuenta que, en muchas ocasiones, la mediación guarda una estrecha relación con los procesos judiciales, pues ésta se encuentra vinculada o tiene carácter complementario a un proceso vivo, supuesto en que hablamos de mediación judicial, intrajudicial o mediación conectada con el tribunal ${ }^{12}$, institución que también existe en los países de nuestro entorno ${ }^{13}$.

Sobre la base de los elementos apuntados, y pese a que la mediación va a revestir distintas características en función de las partes implicadas, el tipo de conflicto o el ámbito material en el que se dé, podemos, de manera amplia, definir la mediación como un sistema alternativo de resolución de conflictos en el que interviene un tercero que, actuando con imparcialidad, ayuda a las partes a comunicarse para resolver su controversia de común acuerdo.

Así, sin perder de vista que el objetivo de la mediación es que las partes lleguen a un acuerdo de manera voluntaria, la misma estará regida por una serie de principios dirigidos a obtener esta finalidad, principios rectores de la mediación entre los que se encuentran el principio de voluntariedad, imparcialidad e igualdad entre las partes y confidencialidad ${ }^{14}$.

En relación a estos principios, la voluntariedad es, con toda probabilidad, el principio de la mediación que suscita más controversia. Mientras resulta indiscu-

12 Sobre el tema, Soleto MuÑoz, H., "La mediación conectada con los tribunales", en Soleto MuÑOZ, H. (Dir.), Mediación y resolución de conflictos: técnicas y ámbitos, Ed. Tecnos, Madrid, 2011. Págs. 245 y siguientes.

${ }^{13}$ En este sentido, Rapport d'Information sur la médiation en Europe, Assamblée nationale, 13 de febrero de 2007, citado en Soleto Muñoz, H. (2011): Pág. 252.

${ }^{14}$ Respecto al principio de confidencialidad, debemos destacar que hay ciertas excepciones al mismo, como sucede, por ejemplo, cuando con ocasión de la mediación, se conocen casos de violencia o abuso 
tible que la voluntariedad estará presente a lo largo del procedimiento así como en la adopción de la resolución final, se plantean dudas acerca de si el sometimiento a la mediación debe ser necesariamente voluntario o, por el contrario, en determinados supuestos puede establecerse, ya sea ex lege o mediante pronunciamiento judicial, la obligatoriedad de asistir, como mínimo, a la primera sesión de mediación, denominada informativa.

Ante esta disyuntiva, parece que la derivación judicial se encuentra aceptada por la mayoría de la doctrina ${ }^{15}$ y empieza a preverse en algunas normas ${ }^{16}$; mientras que el establecimiento de la mediación obligatoria por imperativo legal plantea más reticencias, pese a la cobertura que le concede la normativa europea ${ }^{17}$.

Por su parte, la Ley 5/2012, de 6 de julio, de mediación en asuntos civiles y mercantiles (sobre la que luego profundizaremos) viene a remarcar el carácter voluntario que, con carácter general, preside la mediación (art. 6).

Atendiendo a las características y principios de la mediación a los que acabamos de referirnos, podemos afirmar que, con carácter general, la mediación presenta una serie de ventajas sobre los demás métodos de resolución de conflictos y, especialmente, frente a la vía judicial, entre las que podemos destacar: el ahorro, la rapidez, la flexibilidad, la apaciguación o la satisfacción personal ${ }^{18}$.

contra menores, hechos que puedan ser constitutivos de delito, situaciones que pongan en peligro la integridad física o psicológica de una persona, ante la presencia de un hecho o acto ilícito. En estos supuestos, la confidencialidad decae y el mediador deberá poner dichas situaciones en conocimiento de la autoridad competente para adoptar las medidas oportunas. Cavaldi, M.C y Quinteros Avellaneda, L.G, Introducción a la gestión no adversarial de conflictos. Instituto Complutense de Mediación y Resolución de Conflictos, Madrid, 2010. Pág. 139.

15 Se entiende así que, siempre y cuando se respeten una serie de pautas, la voluntariedad no prima respecto a la decisión del juez de derivar, obligatoriamente, a una sesión informativa. BuTTS GRIGGS, Respuestas al cuestionario del CEf sobre mediación, Madrid, 2008; GALEOTE MuÑOz, M. "La necesidad de un método profesional de mediación: la importancia de la intervención del abogado en este proceso", IW Working Paper Derecho, 15 de abril de 2005; Soleto MuÑoz, H. (2011).

16 El Decreto catalán 135/2012, de 23 de octubre, por el que se aprueba el reglamento de la Ley 15/2009, de 22 de julio, de mediación en el ámbito del Derecho privado prevé las derivaciones judiciales a la mediación en su artículo 29.

${ }^{17}$ En este sentido, la Directiva 2008/52/CE del Parlamento Europeo y del Consejo, de 21 de mayo de 2008, sobre ciertos aspectos de la mediación en asuntos civiles y mercantiles establece en su artículo 5.2 que:

"La presente Directiva no afectará a la legislación nacional que estipule la obligatoriedad de la mediación o que la someta a incentivos o sanciones, ya sea antes o después de la incoación del proceso judicial, siempre que tal legislación no impida a las partes el ejercicio de su derecho de acceso al sistema judicial".

18 Sobre el tema: González-Cuéllar Serrano, N. y Penín Alegre, M.L, "Mediación: una aproximación desde el derecho y la psicología” en Mediación: un método de? de conflictos. Estudio interdisciplinar (Coords. Sanz Hermida, Á. Ma y Ortiz Pradillo, J.C.), Ed. Colex, Madrid, 2010. Págs. 10 a 12. 
Ordenadas así las cosas, las ventajas de la mediación lo son, principalmente, en relación a las partes en conflicto, pero éstas se extienden más allá, beneficiando también al conjunto de la ciudadanía así como a las Administraciones Públicas y, en particular, a la Administración de Justicia, pues la mediación, como método alternativo de resolución de conflictos, evita la judicialización de las controversias, reservando la vía judicial para aquéllos conflictos que no puedan ser resueltos de otra manera, permitiendo reducir la carga de trabajo de los tribunales, con el consiguiente ahorro que ello conlleva para todos los ciudadanos. Sobre ello, volveremos más adelante.

\section{Mediación natural, mediación profesional y mediación insti- tucional}

Atendiendo a la definición de mediación que acabamos de esbozar, sus principios y ventajas, podemos deducir fácilmente que, durante muchos años, la mediación se ha desarrollado al margen de cualquier tipo de regulación o control por parte de los poderes públicos, lo que permite establecer una clara distinción entre la denominada mediación natural y la mediación institucional ${ }^{19}$ y, entre las dos categorías anteriores, la mediación de carácter profesional.

En la vida social y desde tiempos inmemoriales, se produce constantemente una mediación que tiene carácter espontáneo, que se desarrolla de manera informal. Este tipo de mediación es la denominada mediación natural, mediación que había sido actitud y función antes que técnica, y que se guiaba por el propio sentido común compartido socialmente. En la actualidad, este tipo de mediación pervive en la familia, el trabajo y otros contextos cotidianos donde cualquiera de sus miembros puede hacer eventualmente de mediador.

La evolución de la mediación natural ha dado paso a la mediación profesional, un proceso de resolución de conflictos, también desarrollado en el ámbito privado, pero mucho más estructurado y en el que la persona que ejerce la mediación tiene una capacitación especial para ejercer las tareas mediadoras ${ }^{20}$. La mediación profesional y el eventual acuerdo que ponga fin a la misma tienen, co-

\footnotetext{
${ }^{19}$ Esta clasificación entre mediación natural e institucional fue señalada por SIX en su obra Dinámica de la mediación, Barcelona, Ed. Paidós, 1997. Citado en Barroso, I., Hermoso, B. y Morente, F., "La mediación institucional ante el conflicto social: ¿Articulación o desarticulación de la participación ciudadana?" en La mediación en tiempos de incertidumbre (Dir. Morente MejíAs, F.), Ed. Dykinson, Madrid, 2010.

${ }^{20}$ La mediación como técnica surgió en el ámbito académico durante los años setenta con el Proyecto Harvard de negociación de FISHER y URY, aplicándose en el terreno laboral para resolver determinados conflictos a través de la intervención de determinadas personas que ayudaban a encontrar una solución de forma más rápida, económica y formativa. GonzÁlez-Cueldar Serrano, N. y Penín Alegre, Maa.L. (2010).
} 
mo decimos, carácter privado, por lo que este proceso se regirá por la autonomía de la voluntad, siendo los únicos límites los que vienen impuestos por los principios que rigen la mediación, a los que ya hemos hecho referencia.

Finalmente, frente a la mediación natural y la mediación profesional, y como culminación de la evolución y perfeccionamiento de la misma, encontramos la mediación institucional, fruto del desarrollo y reglamentación de la mediación por parte de las Administraciones Públicas y de organizaciones de distinta naturaleza que inciden en las relaciones de convivencia. Así, al hablar de institucionalización de la mediación, nos estamos refiriendo al conjunto de acciones impulsadas por las Administraciones Públicas que contribuyen a la organización, implantación y difusión social de la mediación como servicio público.

La mediación institucional es, por tanto, un servicio de carácter público, que se rige imperativamente por una serie de normas preestablecidas que prevén un proceso altamente estructurado, dirigido por un mediador profesional (cuya formación también es objeto de una amplia regulación normativa) y que finaliza en un acuerdo que, normalmente, se constituye como título ejecutivo.

La mediación institucional se desarrollará, con carácter general, en el seno de una Administración Pública. No obstante, también puede suceder que la organización que preste el servicio sea de naturaleza asociativa, pero en este supuesto, y a diferencia de lo que sucede con la mediación profesional (de carácter privado), la promoción, financiación, supervisión y control de la mediación desarrollada por estas entidades serán totalmente públicos, lo que obliga a las entidades mediadoras a aceptar el protocolo de actuación impuesto por la Administración, las condiciones y limitaciones aplicables a la prestación del servicio (especialmente, en relación a la formación de los mediadores) así como los requisitos formales del proceso.

Una vez vistos los distintos tipos de mediación, al objeto de este estudio, vamos a centrarnos en la mediación institucional, por la relevancia que la misma está adquiriendo en el momento actual.

\section{LA MEDIACIÓN INSTITUCIONAL EN EL MOMENTO PRE- SENTE}

\section{El fomento de la mediación institucional por los poderes pú- blicos}

Ya hemos adelantado que la mediación institucional está experimentando en los últimos años un gran impulso por parte de las autoridades públicas, fenóme- 
no que no se ha producido únicamente en España, sino que también es predicable de la mayor parte de países de nuestro entorno ${ }^{21}$. A su vez, este proceso de institucionalización de la mediación ya se había producido años atrás en el derecho estadounidense ${ }^{22}$.

El auge de la mediación institucional al que nos venimos refiriendo se deriva, fundamentalmente, de una serie de problemas que han surgido en el actual contexto social y económico, frente a los cuales, las características y ventajas que presenta la mediación actúan como un auténtico bálsamo.

Actualmente, factores sociales como la globalización, la realización del mercado interior en la Unión Europea, la fuerte intensificación de los intercambios comerciales, el incremento de la movilidad de los ciudadanos, etc. han provocado un aumento exponencial de los conflictos y, por ende, de la procesalización de las disputas ${ }^{23}$; aumento de la litigiosidad que no ha ido acompañado de una mejora en los recursos de la Administración de Justicia, cada vez más escasos como consecuencia de las medidas de racionalización del gasto público adoptadas en el actual contexto de crisis económica ${ }^{24}$.

${ }^{21}$ En el concreto ámbito de la mediación familiar, podemos ver: Family mediation in Europe, proceedings. 4th European Conference on Family Law, Council of Europe Publishing, Strasbourg, 2000.

En el Derecho francés, podemos hacer referencia a FAGET, "La doublé vie de la médiation", Droit et Societé, 29, 1995; Petit, F., Auvergnon, P., Gil y Gil, J.L., Cruz Villalón, J., Trudeau G., Veilleux, D., Le règlement amiable des différends sociaux, Étude juridique: France, Espagne, Québec, L'Harmattan, Paris, 2007.

En Italia, FABIAni, M., "Profili critici del rapporto fra mediaciones e proceso", en fudicium (en línea: http://www.judicium.it/admin/saggi/98/Fabiani.mediazone.pdf); MestiTz, A. y VogLiotTI M., "The rise and growth of mediation in Italy", En Poblet, M., Courts and mediation. New paths for justice, European Presss Academic Publishing, Firenze, 2011; Scarselli, G., "La nuova mediazione e conciliazione: le cose che non vanno", en fudicium (en línea: http://www.judicium.it/adminsaggi/46/scarsell.pdf).

${ }^{22}$ En Estados Unidos el denominado "movimiento de resolución alternativa de conflictos" se inició a finales de los años 60 como consecuencia de la saturación del sistema de justicia norteamericano. Así, la mediación institucional nació en el seno de los juzgados, especialmente los de primera instancia, que decidieron incorporar mediadores voluntarios durante los juicios como recurso alternativo al veredicto (BARroso, I., Hermoso, B. y Morente, F. (2010).

Sobre el tema pueden verse: Bush, R.B., Folger, J., The promise of mediation, San Francisco: Jossey Bass (New and revised edition), 2005; Conference on rules for institutional arbitration and mediation, WIPO publication, 1995.

23 Carretero Morales, E. "La necesidad de cambios en los modelos de solución de conflictos" en Soleto Muñoz, H. (2011).

24 Así, la Ley Orgánica 8/2012, de 27 de diciembre, de medidas de eficiencia presupuestaria en la Administración de Justicia prevé, entre otras, que la actuación de jueces sustitutos y magistrados suplentes sea excepcional, ante circunstancias de necesidad acreditada y motivada (arts. 199, 200, 215 LOPJ, en su nueva redacción). 
Todo ello ha llevado al colapso e ineficiencia de la Administración de Justicia, demostrando así la insuficiencia y obsolencia de los sistemas clásicos de resolución de conflictos y provocando, en algunos casos, situaciones verdaderamente dramáticas, pues no podemos olvidar que lo que está en juego en este caso es el Derecho fundamental a la tutela judicial efectiva que reconoce el art. $24 \mathrm{CE}^{25}$.

Con este telón de fondo, los poderes públicos han tenido que buscar fórmulas para frenar el colapso de la Administración de Justicia, poniéndose en marcha una serie de medidas restrictivas del acceso a la justicia ${ }^{26}$, pero también otras tantas para fomentar el uso de sistemas alternativos de resolución de conflictos, como la mediación, que no sólo descargan de trabajo a la Administración de Justicia, sino también contribuyen a la profundización democrática, al permitir que los particulares resuelvan los conflictos que les afectan sin recurrir al poder de un tercero.

Y es que, tal como señala REDORTA, el derecho a la tutela judicial efectiva no debe identificarse exclusivamente con el acceso a los tribunales, sino también con el derecho a acceder a "los medios apropiados de resolución de conflictos en función de las circunstancias del caso"27. El sistema judicial ha de ser utilizado

${ }^{25}$ En este sentido se pronuncia el Defensor del Pueblo en su informe anual de 2012, en el que se constata el aumento de los retrasos judiciales y dilaciones indebidas, especialmente llamativo en las jurisdicciones social y mercantil, que han experimentado "un preocupante incremento del volumen de trabajo" como consecuencia de la crisis económica.

Respecto a los retrasos que se producen en la jurisdicción social, la Institución destaca el caso de un ciudadano cuyo despido se materializó el mes de noviembre de 2010, y en un relato de su precaria situación económica exponía su preocupación por las dilaciones judiciales en la resolución del recurso de casación que tenía planteado en la Sala Cuarta de lo Social del Tribunal Supremo. Como consecuencia de la intervención del Defensor del Pueblo, el 5 de junio de 2012 le fue notificada la sentencia.

Asimismo, la Institución también ha constatado que en numerosos casos se están fijando vistas para el año 2014 y sucesivos, destacando el caso de un procedimiento abreviado pendiente de señalamiento desde octubre de 2010; y el señalamiento de una vista para el 12 de enero de 2017 en el Juzgado Contencioso Administrativo número 5 de Madrid.

${ }^{26}$ Entre dichas medidas, destaca la aprobación de la Ley 10/2012, de 20 de noviembre, por la que se regulan determinadas tasas en el ámbito de la Administración de Justicia y del Instituto Nacional de Toxicología y Ciencias Forenses. Sobre su finalidad, el Preámbulo de esta norma se pronuncia en los siguientes términos: "con esta asunción por los ciudadanos que recurren a los tribunales de parte del coste que ello implica se pretende racionalizar el ejercicio de la potestad jurisdiccional, al mismo tiempo que la tasa aportará unos mayores recursos que permitirán una reforma del sistema judicial".

Actualmente, la norma se encuentra recurrida ante el Tribunal Constitucional por entender que la misma vulnera el derecho constitucional a la tutela judicial efectiva (art. $24 \mathrm{CE}$ ).

27 Redorta, J., "La justicia del futuro", en Simposio sobre Tribunales y Mediación. Nuevos caminos para la fusticia. Comunicaciones. Ed. Gemme, Barcelona 2009, Pág. 6. 
únicamente cuando no exista otro método más adecuado o más eficiente para la resolución del conflicto, pues la "inercia" a recurrir a los tribunales nos impide ver que, en muchas ocasiones, las características del conflicto hacen más recomendable recurrir a otras vías para solventar el mismo ${ }^{28}$.

Las ideas anteriores se han traducido en una clara apuesta de fomento y promoción de las ADR y, en particular, de la mediación, por parte de los poderes públicos.

Así, a nivel Comunitario, en los últimos años, se han sucedido diversas recomendaciones del Consejo de Europa, que fructificaron primero en el Libro Verde de la Comisión sobre las modalidades alternativas de solución de conflictos en el ámbito del Derecho civil y Mercantil (2002); y, posteriormente, en la Directiva 2008/52/CE del Parlamento Europeo y del Consejo, de 21 de mayo de 2008, sobre ciertos aspectos de la mediación en asuntos civiles y mercantiles (en adelante Directiva 2008/52/CE).

A nivel interno, el Plan Estratégico de Modernización del Sistema de Justicia 2009-2012, presentado por el Ministerio de Justicia dentro del Eje Estratégico "Un servicio público orientado a las personas" prevé la adopción de "una serie de medidas organizativas y legislativas que permitirán el progresivo establecimiento de procedimientos y sistemas para una solución de los conflictos jurídicos alternativa a la vía judicial" y, en concreto, la potenciación de "mecanismos como la mediación, la conciliación o el arbitraje en distintas jurisdicciones", para que el recurso a los tribunales se configure así como la última ratio ${ }^{29}$.

En definitiva, una serie de iniciativas que sitúan a la mediación institucional en un primer plano del contexto político y jurídico actual. Muestra de ello es el gran número de normas sectoriales, tanto estatales como autonómicas, que prevén acudir a la mediación institucional cuando surjan conflictos relacionados con la materia objeto de regulación ${ }^{30}$.

${ }^{28}$ Así lo pone de manifiesto el estudio realizado por PASTOR PRIETO, S. ("Eficiencia y Medios Alternativos", en Medios Alternativos de Solución de Controversias, Anuario de la Facultad de Derecho de la Universidad Autónoma de Madrid, Boletín Oficial del Estado, Madrid, 2008. Págs. 60 y ss.), que pone de relieve que más de la mitad de los casos civiles que se tramitan en España son de mero trámite, como las separaciones o divorcios de muto acuerdo, que podrían ser desempeñados por otras personas u organismos distintos de los Juzgados; o que una cuarta parte de los asuntos civiles tiene una cuantía inferior a mil euros.

29 Diario "La Ley", 15 de octubre de 2010. Citado en Carretero Morales, E. (2011).

${ }^{30}$ A modo de ejemplo, y entre las últimas normas que se han dictado, podemos hacer referencia a las siguientes: Ley Foral 12/2013, de 12 de marzo, de emprendedores y de trabajo autónomo de Navarra (art. 


\section{Marco normativo de la mediación institucional en España}

Este impulso de la mediación por parte de los poderes públicos al que nos venimos refiriendo, se ha traducido, como decimos, en un aumento de las normas sectoriales que prevén el recurso a la mediación, pero también en la aprobación de diversas normas que tienen por objeto dotar a la mediación institucional de un marco normativo de carácter general.

Partiendo de que la mediación puede versar sobre materias de lo más variado, siendo así una institución de carácter transversal, el reparto competencial previsto en la Constitución ha hecho que tanto el legislador estatal como el autonómico hayan entrado a regularla.

\section{A. La regulación estatal}

A excepción de alguna norma esporádica en el ámbito laboral ${ }^{31}$, hasta la reciente Ley 5/2012, de 6 de junio, de mediación en asuntos civiles y mercantiles ${ }^{32}$, y su desarrollo reglamentario a través del Real Decreto 980/2013, de 13 de diciembre se carecía en España de una ordenación general de la mediación aplicable a los diversos asuntos civiles y mercantiles, deficiencia que era suplida, como veremos, gracias a la legislación autonómica en este ámbito.

La Ley 5/2012 transpone al Derecho español la ya citada Directiva 2008/52/CE 33 , la cual, a su vez, tiene por objeto facilitar el acceso a las moda-

6); Ley 14/2012, de 26 de diciembre, por la que se aprueban medidas urgentes para paliar los daños producidos por los incendios forestales y otras catástrofes naturales ocurridos en varias Comunidades Autónomas; Ley 5/2013, de 12 de abril, de defensa de los consumidores en la Comunidad Autónoma de la Rioja.

${ }^{31}$ Históricamente, la primera norma estatal referida a la mediación fue el Real Decreto Ley 5/1979, de 26 de enero, sobre creación del Instituto de Mediación, Arbitraje y Conciliación, organismo autónomo adscrito al Ministerio de Trabajo con diversas funciones en el ámbito laboral, entre la que destacaban las de mediación, arbitraje y conciliación en el ámbito laboral. Actualmente, la prestación de este servicio depende de las Administraciones autonómicas, en las que existe un Servicio de Mediación, Arbitraje y Conciliación (SMAC).

${ }^{32}$ Los aspectos esenciales de esta norma y las novedades que la misma ha representado son objeto de estudio en: AAVV (Dir. C. Fernández Canales; Coord. M. Blanco Carrasco), Mediación en asuntos civiles y mercantiles: comentarios a la Ley 5/2012, Madrid: Reus, 2012; BARONA VILAR, S., Mediación en asuntos civiles y mercantiles en España: tras la aprobación de la Ley 5/2012, de 6 de julio, de mediación en asuntos civiles y mercantiles, Tirant lo Blanch, Valencia, 2013; Viola Demestre, I., "La mediación en asuntos civiles y mercantiles (breves notas a la Ley 5/2012, de 6 de julio)", en Revista Chilena de Derecho y Ciencia Política, AgostoDiciembre 2012, págs. 159-187.

${ }^{33}$ El plazo de incorporación de la Directiva finalizó el 21 de mayo de 2011 retraso que justificó que la Ley 5/2012 se aprobara inicialmente por Decreto Ley. 
lidades alternativas de solución de conflictos y fomentar la resolución amistosa de litigios promoviendo la mediación, estableciendo unas normas mínimas para promover la mediación en los litigios en asuntos civiles y mercantiles. La Directiva únicamente resulta de aplicación a los conflictos transfronterizos, aunque deja abierta la posibilidad de que los Estados Miembros decidan también aplicarla a los procedimientos de mediación de carácter nacional. En el caso de España, se ha optado por esta última alternativa, pues la regulación contenida en la Ley 5/2012 resulta de aplicación tanto a los conflictos transfronterizos como nacionales (art. 2).

Por otro lado, con la aprobación de la Ley 5/2012 también se da cumplimiento al mandato contenido en la Disposición final tercera de la Ley 15/2005, de 8 de julio, por la que se modifica el Código Civil y la Ley de Enjuiciamiento Civil en materia de separación y divorcio, que encomendaba al Gobierno la remisión a las Cortes Generales de un proyecto de ley sobre mediación ${ }^{34}$.

Debemos tener en cuenta que la Ley 5/2012 se ha dictado en base a las competencias del Estado en materia de legislación mercantil, procesal y civil (art. 149.1 CE), articulando así un marco general para el ejercicio de la mediación, sin perjuicio de las disposiciones que dicten las Comunidades Autónomas en el ejercicio de sus competencias. Así, a falta de sometimiento expreso o tácito a la Ley $5 / 2012$, la misma será aplicable cuando al menos una de las partes tenga su domicilio en España y la mediación se realice en territorio español (art. 2.1 in fine).

En cuanto al ámbito de aplicación material (art. 2.2), la Ley se aplica en las mediaciones civiles o mercantiles, quedando excluida expresamente la mediación penal, la mediación con las Administraciones públicas, la mediación laboral y la mediación en materia de consumo, que se regirán por las respectivas normas sectoriales.

Así, y de conformidad con lo anterior, la finalidad de la Ley 5/2012 es sentar las bases de la mediación institucional con carácter general y favorecer esta alternativa frente a la solución judicial del conflicto, haciendo especial hincapié en la figura de mediador como la pieza esencial del modelo (arts. 11 a 14), las fases del procedimiento de mediación (arts. 16 a 23) y el acuerdo de mediación como título ejecutivo (arts. 25 a 27).

34 Así, la Disposición final tercera de la Ley 15/2005 establecía:

"El Gobierno remitirá a las Cortes un proyecto de ley sobre mediación basada en los principios establecidos en las disposiciones de la Unión Europea, y en todo caso en los de voluntariedad, imparcialidad, neutralidad y confidencialidad y en el respeto a los servicios de mediación creados por las Comunidades Autónomas". 
Además, y para cumplir con las finalidades previstas en esta ley, su artículo 5 prevé la existencia de una serie de entidades que tienen la consideración de "instituciones de mediación", considerando como tales "las entidades públicas o privadas, españolas o extranjeras, y las corporaciones de derecho público que tengan entre sus fines el impulso de la mediación, facilitando el acceso y la administración de la misma, incluida la designación de mediadores, debiendo garantizar la transparencia en la referida designación (...)". Entre estas instituciones de mediación, la ley hace referencia de manera expresa a los Colegios Oficiales y las Cámaras Oficiales de Comercio Industria y Navegación, modificando sus respectivas normas reguladoras ${ }^{35}$.

Por su parte, el Reglamento de desarrollo de la Ley 5/2012 (Decreto 980/2013), pone especial atención en algunos de los aspectos clave en la regulación de la mediación institucional, esto es: la formación del mediador (arts. 3 a 7); el Registro de Mediadores e Instituciones de Mediación (arts. 8 a 25); el aseguramiento de la actividad de mediación (arts. 26 a 29) y el procedimiento de mediación por medios electrónicos (arts. 30 a 38).

\section{B. La regulación autonómica}

Como hemos adelantado, la regulación estatal sobre mediación en España se ha hecho esperar, provocando un vacío en este ámbito que, durante años, fue suplido por las distintas legislaciones autonómicas.

En virtud de los títulos competenciales reconocidos en sus respectivos Estatutos de Autonomía ${ }^{36}$, los legisladores autonómicos fueron los que tomaron las riendas en el ámbito de la mediación, regulando este método de resolución alternativa de conflictos en el ámbito de sus respectivas competencias, especialmente en materia de familia.

\footnotetext{
${ }^{35}$ La Disposición Final primera modifica en este sentido la Ley 2/1974, de 13 de febrero de Colegios Profesionales, añadiendo una letra ñ) a su artículo 5, previendo así entre las finalidades de los Colegios Profesionales: "Impulsar y desarrollar la mediación (...)".

En el mismo sentido se modifica también el artículo 2 de la Ley 33/1993, de 22 de marzo, Básica de las Cámaras Oficiales de Comercio, Industria y Navegación.

${ }^{36}$ A modo de ejemplo, el art. 71.26 del Estatuto d Autonomía de Aragón (Ley Orgánica 5/2007, de 20 de abril) prevé la competencia autonómica exclusiva en materia de consumo, "que, en todo caso, comprende (...) la regulación de los órganos y procedimientos de mediación"; como también lo prevé el art. 30.47 del Estatuto de Autonomía de les Illes Balears (Ley Orgánica 1/2007, de 28 de febrero).

En el caso de Andalucía, su Estatuto de Autonomía (Ley Orgánica 2/2007, de 19 de marzo), prevé la competencia exclusiva en la mediación en materia de consumo (art. 58.2-4) y en el ámbito laboral (art. 63.1-6); reconociendo también, en el Capítulo dedicado a la Administración de Justicia, una competencia general para establecer los instrumentos de mediación y conciliación en la resolución de conflictos en materia de su competencia (art. 150.2).
} 
En particular, el legislador catalán fue pionero a la hora de dar cobertura normativa a la mediación en el ámbito familiar, a través de la Ley 1/2001, de 15 de marzo, de mediación familiar, hoy derogada por la Ley 15/2009, de 22 de julio, de mediación en el ámbito del Derecho privado, a la que luego nos referiremos.

La Ley 1/2001 inspiró muchas otras leyes autonómicas en materia de mediación familiar ${ }^{37}$. Así, tras la misma, se dictaron las siguientes normas: Ley de Galicia 4/2001, de 31 de mayo, reguladora de la mediación familiar; Ley de la Comunidad Valenciana 7/2001, de 26 de noviembre, reguladora de la mediación familiar; Ley de Castilla la Mancha 4/2005, de 24 de mayo, del servicio social especializado de mediación familiar; Ley de Castilla y León 1/2006, de 6 de abril, de mediación familiar; Ley de la Comunidad de Madrid 1/2007, de 21 de febrero, de mediación familiar; Ley del Principado de Asturias 3/2007, de 23 de marzo, de mediación familiar; Ley del País Vasco 1/2008, de 8 de febrero, de mediación familiar; Ley de la Comunidad Autónoma de Andalucía 1/2009, de 27 de febrero, reguladora de la mediación familiar; Ley de las Illes Balears 14/2010, de 9 de diciembre, de mediación familiar ${ }^{38}$; Ley de Aragón 9/2011, de 24 de marzo, de mediación familiar; Ley de Cantabria 1/2011, de 28 de marzo, de mediación de Cantabria.

Todas ellas, con la excepción de la Ley cántabra 1/2011, son normas de mediación pero circunscritas al concreto ámbito de la familia, aunque a través de las mismas ha sido posible entrar a regular aspectos generales de la mediación, supliendo así la carencia de la legislación estatal en este ámbito.

Actualmente, en el contexto de impulso de la mediación institucional al que nos hemos referido, auguramos la promulgación de una segunda generación de leyes autonómicas de mediación, que se extenderán a otros ámbitos distintos del familiar, ampliando su ámbito material de aplicación. Ello ya ha sucedido en Cantabria (Ley cántabra 1/2011, ya citada) y, primeramente, en Cataluña, donde se ha dictado la Ley 15/2009, de 22 de julio, de mediación en el ámbito del Derecho Privado que procedemos a analizar.

${ }^{37}$ Las distintas normas autonómicas en materia de mediación tienen unos elementos estructurales muy similares, pues todas ellas se inspiran en la Recomendación (1998) del Comité de Ministros del Consejo de Europa.

Sobre la legislación autonómica en materia de mediación: AAVV, Duplà MARín, MaT. (Coord.), El régimen jurídico de la mediación familiar en España. Análisis de la normativa autonómica, Ed. Andavira, Santiago de Compostela, 2012. Ver también Libro Blanco de la Mediación en Cataluña, Generalitat de Catalunya i Obra Social "La Caixa", págs. 154 y ss. En línea: http://www.llibreblancmediacio.com/

38 Norma que derogó la Ley de las Illes Balears 18/2006, de 22 de noviembre, de mediación familiar. 
C. La Ley catalana 15/2009, de 22 de julio, de mediación en el ámbito del Derecho privado y su desarrollo reglamentario a través del Decreto 135/2012, de 23 de octubre.

El Estatuto de Autonomía de Cataluña (Ley Orgánica 6/2006, de 19 de julio) es, en comparación con los demás Estatutos autonómicos, el que dedica más preceptos a la mediación. En primer lugar, en el capítulo dedicado a las competencias de la Generalitat sobre Administración de Justicia (Título III; Capítulo III), se prevé una competencia general para "establecer los instrumentos y procedimientos de mediación y conciliación en la resolución de conflictos en las materias de su competencia" (art. 106.2). Además, y en segundo lugar, el Estatut contempla la mediación como un instrumento para hacer efectivos los principios rectores que inspiran la actuación de los poderes públicos (Título I, Capítulo V), en concreto, como una técnica para promover la cohesión y bienestar sociales (art. 42.7), para resolver los conflictos de intereses entre los diferentes agentes sociales del ámbito socioeconómico (art. 45.6) y para proteger a los consumidores (art. 49.2). Finalmente, la mediación se encuentra prevista en distintos preceptos dedicados a las materias de las competencias (Título IV, Capítulo II), en particular, en materia de consumo (art. $123 \mathrm{c}$ ), cooperativas (art. $124.2 \mathrm{~h}$ ) ${ }^{39}$, deporte (art. $134.1 \mathrm{~b}$ ), transportes (art. $169.1 \mathrm{e}$ ), laboral (art. $170 \mathrm{k}$ ) y turismo (art. 171).

La relevancia de la mediación en el ordenamiento jurídico catalán no es sólo predicable del Estatuto de Autonomía pues, como hemos avanzado, esta Comunidad Autónoma fue la primera en dotar a la mediación familiar de una regulación legal a través de la ya citada Ley $1 / 2001$. Pese al avance que, en su momento, representó la Ley 1/2001, durante los últimos años de su aplicación, se produjeron diversas circunstancias que hicieron patente la necesidad de reformarla ${ }^{40}$, reforma que se produjo con la Ley 15/2009, de 22 de julio, de mediación en el ámbito del derecho privado (en adelante Ley 15/2009) y su desarrollo reglamentario, contenido en el Decreto 135/2012, de 23 de octubre (en adelante Decreto 135/2012).

39 Este recepto encuentra su desarrollo reglamentario en el Decreto 171/2009, de 3 de noviembre, por el que se aprueba el Reglamento de los procedimientos de conciliación, mediación y arbitraje ante el Consejo Superior de la Cooperación.

${ }^{40}$ Así, la propia Ley 15/2009, de 22 de julio, de Mediación en el ámbito del Derecho Privado de Cataluña establece en su Preámbulo que, esencialmente, son tres los factores que incidieron en la necesidad de reformar la Ley 1/2001. Dichos factores son los siguientes: en primer lugar, la experiencia obtenida con la implantación efectiva del sistema; en segundo lugar, el debate en instancias europeas en materia de mediación, provocado esencialmente por la publicación en 2002 del Libro verde sobre las modalidades alternativas de resolución de conflictos en el ámbito del Derecho civil y mercantil y la aprobación de la Directiva 2008/52/CE; finalmente, y en tercer lugar, la modificación de la Ley de Enjuiciamiento Civil in- 
Así, la Ley 15/2009 ha permitido superar algunos de los inconvenientes que planteaba la Ley 1/2001, gracias, principalmente, a que se trata de una ley de mediación con un ámbito de aplicación objetivo no circunscrito únicamente al ámbito familiar, a diferencia de lo que sucedía con su predecesora ${ }^{41}$.

La Ley 15/2009 ofrece así, en el ámbito de Cataluña, un marco normativo general para la mediación institucional en el ámbito del Derecho privado, refiriéndose a la mediación como un servicio público, que en Cataluña es gestionado por el Centro de Mediación de Derecho Privado de Cataluña, junto con "otras entidades públicas" que colaboran con el primero, identificadas con los Colegios Profesionales y las Entidades Locales. Como veremos, también pueden colaborar con el Centro de Mediación de Derecho Privado de Cataluña las asociaciones profesionales que cumplan determinados requisitos.

Las novedades que presenta el nuevo marco normativo de la mediación institucional en Cataluña, plasmado en la Ley 15/2009 y en el Decreto 135/2012, se pueden sintetizar de la siguiente manera:

(i) La mediación institucional objeto de regulación no se reduce a la mediación familiar, sino que ésta abarca una serie de conflictos que se encuadran en la categoría más amplia de mediación de derecho privado (art. 2 Ley 15/2009), que incluye la mediación familiar y la mediación civil, resultando así de aplicación a conflictos como los que surgen en el ámbito de las comunidades de propietarios, de la vida asociativa y fundacional y otros litigios nacidos en la comunidad que son impropiamente judicializados y que se caracterizan por la necesidad de las partes de mantener una relación viable en el futuro.

(ii) El Centro de Mediación Familiar de Cataluña es adaptado a los nuevos ámbitos de mediación regulados en la ley, pasando a ser el Centro de Mediación de Derecho Privado de Cataluña, impulsor principal del procedimiento de mediación y órgano de apoyo de referencia tanto de los mediadores como de las personas que desean someterse a mediación para resolver sus controversias.

troducida por la Ley 15/2005, de 8 de julio, que establece específicamente la mediación familiar en el ámbito de los procedimientos de familia.

41 Tal como señala el Preámbulo de la Ley 15/2009: "los reducidos ámbitos previstos inicialmente para aplicar la Ley han sido un obstáculo para acoger determinados conflictos del círculo más próximo a las personas para las que la mediación se revela muy útil, como los conflictos entre padres e hijos o las disputas familiares por las sucesiones. La utilización de la metodología de la mediación en torno a las familias afectadas por los procesos de discapacidad psíquica o de enfermedades degenerativas que limitan la capacidad de obrar es otro de los campos que justifican la modificación legal”. 
(iii) Se prevé la existencia de una serie de entidades, denominadas entidades en el ámbito de la mediación o entidades mediadoras, que colaborarán en el desarrollo de las funciones que tiene encomendadas el Centro de Mediación de Derecho Privado de Cataluña. Entre estas entidades, se encuentran los Colegios Profesionales (art. 2 Decreto 135/2012), las asociaciones profesionales acreditadas (art. 3 Decreto 135/2012) así como las Administraciones locales y "otras entidades públicas" (art. 4.1 Decreto 135/2012), aunque a estas últimas no les resultará de aplicación el procedimiento de mediación previsto en el Reglamento (art. 4.2 Decreto 135/2012).

(iv) Se refuerza la profesionalización de las personas mediadoras, poniendo especial énfasis en su formación así como en su deber de inscribirse en uno de los registros que prevé el reglamento ${ }^{42}$.

En relación a la formación de las personas mediadoras (arts. 17 a 24 Decreto $135 / 2012$ ), se trata de una regulación dirigida a garantizar su profesionalidad, estableciendo los requisitos de la formación, tanto inicial como continuada, que éstas deben llevar a cabo; y atribuyendo a determinados entes, entre los que destacan los Colegios Profesionales, importantes funciones asociadas a la formación y posterior salvaguarda de las obligaciones con la que tienen que cumplir los mediadores.

En definitiva, se trata de una regulación que pretende reforzar y dotar de mayor rigor a la mediación institucional, implicando a diversos operadores jurídicos, incluidos los Colegios Profesionales; y ofreciendo a los ciudadanos que pretenden recurrir a este sistema alternativo de resolución de conflictos una mayor seguridad jurídica.

42 El Capítulo II del Decreto 135/2012 regula los registros generales de personas mediadoras, distinguiendo, por un lado, entre los Registros generales de personas mediadoras del Centro de Mediación de Derecho Privado de Cataluña (arts. 5 a 12), en los que hay un registro de personas mediadoras en el ámbito familiar y otro en el ámbito del Derecho privado; y, por otro lado, el Registro de servicios de mediación ciudadana (arts. 13 a 16), para aquellos servicios de mediación creados por Administraciones locales y otras entidades públicas. 


\section{EL PAPEL DE LOS COLEGIOS PROFESIONALES EN EL SE- NO DE LA MEDIACIÓN INSTITUGIONAL: SU GONFIGU- RACIÓN GOMO INSTITUCIONES DE MEDIACIÓN}

Ya hemos visto como las distintas normas en materia de mediación coinciden en otorgar a los Colegios Profesionales la condición de entidad mediadora o institución de mediación. Este reconocimiento conlleva que se atribuyan a los Colegios Profesionales importantes funciones públicas en el ámbito de la mediación institucional.

Entre estas funciones públicas, se encuentra la organización, por el propio Colegio Profesional, de un servicio público de mediación, en los términos y condiciones que prevea la legislación aplicable. Asimismo, el estatus de institución de mediación conlleva que los Colegios Profesionales lleven a cabo diversas funciones públicas vinculadas a la mediación, y que abarcan desde la formación y control de las personas mediadoras, aspectos diversos del procedimiento de mediación, así como otras funciones, dirigidas, con carácter general, al desarrollo e impulso de esta institución.

\section{Una cuestión previa: Colegios Profesionales que tienen la con- sideración de entidades de mediación}

La participación de los Colegios Profesionales en la mediación institucional obedece a la consideración de éstos como entidades mediadoras o instituciones de mediación; lo cual, necesariamente, lleva a plantearnos si todos los Colegios Profesionales tienen la condición de entidades mediadoras.

Al respecto, el ya citado artículo 5 de la Ley 5/2012 establece que se consideran instituciones de mediación "las entidades públicas o privadas, españolas o extranjeras, y las corporaciones de derecho público que tengan entre sus fines el impulso de la mediación, facilitando el acceso y la administración de la misma, incluida la designación de mediadores, precepto que no ha recibido más concreción en el R.D. 980/2013.

Atendiendo a la redacción de este precepto, parece que la adquisición de la condición de institución de mediación por parte de los Colegios Profesionales quedaría subordinada a que el Colegio previera en sus estatutos, u otra norma colegial, que entre sus fines se encuentra "el impulso de la mediación". No obstante, esta finalidad mediadora se ha establecido ex lege, pues la Disposición Final Primera de la propia Ley 5/2012 ha modificado el artículo 5 de la Ley estatal de Colegios Profesionales, añadiendo a las funciones de los mismos: "Impulsar y desarrollar la mediación, así como desempeñar funciones de arbitraje, 
nacional e internacional, de conformidad con lo establecido en la legislación vigente" 43 .

A sensu contrario, la normativa catalana en materia de mediación restringe la consideración de Colegio Profesional en el ámbito de la mediación, al establecer que lo serán, en todo caso, los Colegios de abogados, psicólogos, trabajo social, educadores y educadoras sociales y pedagogos; y, en relación a los demás Colegios, sólo aquellos que firmen convenios de colaboración con el departamento competente en materia de Derecho civil (art. 2.1 Decreto 135/2012).

A nuestro parecer, esta previsión resulta contraria a derecho por dos motivos. En primer lugar, la Ley catalana 15/2009 dedica diversos preceptos a las funciones de los Colegios Profesionales en el marco de la mediación institucional, sin limitar la consideración de Colegio Profesional en el ámbito de la mediación a los Colegios referidos ni establecer la necesidad de firmar ningún convenio para los demás, por lo que no puede establecerse una medida restrictiva de este tipo vía reglamento. En segundo lugar, el art. 15 ñ) LCP fue introducido por la Ley 5/2012, de carácter básico según su Disposición Final sexta, por lo que la previsión que establece que todos los Colegios Profesionales tienen entre sus fines el impulso de la mediación (y, por ende, la condición de entidad mediadora según la Ley 5/2012), debe prevalecer.

Dicho lo anterior, debemos tener en cuenta que las obligaciones que impone la legislación estatal para las instituciones mediadoras son relativamente laxas, estableciendo únicamente que deben facilitar el acceso y la administración de la misma, incluida la designación de mediadores. Por el contrario, en el caso de la normativa catalana, tal como veremos, se establecen unas obligaciones mucho más amplias, entre las que se incluye la formación de los mediadores, deberes registrales, potestades sancionadoras sobre los mediadores, etc. pudiendo darse el supuesto de Colegios Profesionales que no cuentan con los recursos o medios para desarrollar estas funciones.

Una posible solución ante esta contradicción entre normativa estatal y autonómica, sería reconocer el carácter de entidad mediadora de todos los Colegios Profesionales en los términos que establece la legislación estatal (de carácter básico); mientras que el desempeño de las demás competencias y potestades previstas en la legislación autonómica se predicaría únicamente de los Colegios Profe-

${ }^{43} \mathrm{El}$ reconocimiento de esta función se mantiene, con este mismo redactado, en el Anteproyecto de Ley de Servicios Profesionales de 2 de agosto de 2013, en su artículo 34.2 f). 
sionales previstos expresamente en el art. 2.2 Decreto 135/2012 y de todos aquéllos otros que así lo asumieran de forma voluntaria, mediante convenio ${ }^{44}$.

En este entramado normativo, pueden tener un papel destacado los estatutos y reglamentos colegiales. Así, partiendo de que todos los Colegios Profesionales son, en los términos de la legislación estatal, entidades mediadoras, cada Colegio, a través de sus estatutos o de un reglamento de mediación, puede diseñar, de manera más o menos amplia (de acuerdo con la legislación autonómica), su configuración como entidad mediadora, previendo las funciones que quiere desarrollar como tal, los términos concretos de la organización del servicio público de mediación, etc.

\section{La organización de un servicio público de mediación por par- te de los Colegios Profesionales}

A. Tipos de mediación que pueden llevar a cabo los Colegios Profesionales. Mediación privada vs. Mediación pública

Como ya ha puesto de relieve la doctrina ${ }^{45}$, los Colegios Profesionales tienen un régimen verdaderamente singular, pues son Corporaciones de Derecho público (art. 1 LCP), con fines eminentemente públicos, como la ordenación de la profesión o la protección de los intereses de los destinatarios de los servicios profesionales; pero también persiguen, a su vez, intereses de carácter claramente privado, entre los que destaca la defensa de los intereses de sus colegiados, lo que les asemeja a las asociaciones profesionales.

Esta confluencia de intereses públicos y privados ha llevado a afirmar la naturaleza dual o bifronte de los Colegios Profesionales, dualidad que también se refleja en las actuaciones mediadoras que llevan a cabo los Colegios Profesionales, permitiendo distinguir entre el ejercicio de la mediación privada, por un lado; y, por otro, la prestación de un servicio público de mediación.

a) La mediación privada. Los Colegios Profesionales pueden desarrollar tareas de mediación en el ámbito de los intereses privados o corporativos que estos persiguen. Así, pueden darse dos tipos de mediación de carácter privado: la mediación corporativa y la mediación profesional.

\footnotetext{
${ }^{44}$ Esta interpretación se adecuaría así, al inciso final del art. 2.1 Decreto 135/2012 que establece como "fin" de los convenios de colaboración "desarrollar las funciones que les asigna la Ley y el Reglamento".

45 Sobre el tema, puede consultarse la literatura jurídica citada en referencia al debate sobre la naturaleza jurídica de los Colegios Profesionales. Ver nota al pie núm. 6.
} 
La mediación corporativa es aquella en la que, al menos una de las partes implicadas en el conflicto sometido a mediación, es miembro del Colegio Profesional. Así, dicha mediación corporativa puede versar sobre controversias surgidas entre dos o más colegiados o, incluso, entre uno o más colegiados y el propio Colegio Profesional; así como intentar poner fin a una controversia surgida entre uno o más colegiados y el tercero o terceros destinatarios de sus servicios profesionales ${ }^{46}$.

Por otra parte, la mediación profesional tiene lugar cuando el Colegio Profesional hace uso de su infraestructura para prestar un servicio de medición profesional de carácter privado, en el que las dos partes en conflicto son ajenas al Colegio pero el mediador es un profesional colegiado. En este caso, estamos ante un servicio privado de mediación ${ }^{47}$, pues lo que hace el Colegio es poner a disposición de los colegiados una serie de instalaciones y recursos que les facilitan ejercer la mediación cuando la misma se encuentre dentro de las tareas que éstos desarrollan en el ámbito de su actividad profesional. Para el desarrollo de esta mediación profesional, los Colegios Profesionales pueden crear centros de mediación privados, siendo un ejemplo de ello el CEMICAB, el Centro de Mediación del Ilustre Colegio de Abogados de Barcelona ${ }^{48}$, cuya finalidad es promover e intervenir en el ámbito de la mediación, facilitando a los interesados, ya sean ciudadanos, abogados o instituciones, una relación de profesionales que acrediten una experiencia y/o formación previa como mediadores, prestando un servicio técnico de apoyo al mediador, custodiando certificaciones de mediación, etc.

Atendiendo a lo anterior, los dos tipos de mediación de carácter privado que desarrollan los Colegios Profesionales (corporativa y profesional) tienen en común que se desarrollan de acuerdo a un procedimiento estructurado, bajo la di-

\footnotetext{
${ }^{46}$ En este supuesto, el art. 27.4 de la Directiva de Servicios prevé que, cuando en el seno de una asociación u organismo profesional esté previsto el recurso a un mecanismo de resolución extrajudicial, los Estados Miembros tomarán las medidas necesarias para que se informe de ello al destinatario, lo mencionen en todo documento en que se presente de forma detallada uno de sus servicios e indiquen la forma de acceder a información detallada sobre las características y condiciones de uso de este mecanismo.

${ }^{47}$ En la legislación catalana de mediación esta figura está contemplada de forma expresa en la Disposición Adicional Segunda del Decreto 135/2012, que los define en su apartado 1 en los siguientes términos:

"Los servicios privados de mediación son los que llevan a cabo actuaciones de mediación no sujetas a las tarifas del Centro de Mediación de Derecho Privado de Cataluña, y al margen de las actuaciones que en esta materia prestan el Centro de Mediación de Derecho Privado de Cataluña y las entidades que colaboran con el Centro".

48 http://www.cemicab.es/
} 
rección de una persona que tiene algún tipo de preparación para llevar a cabo esta tarea y que, en principio, se regirán según las reglas de la autonomía de la voluntad o, en su caso, por los reglamentos o protocolos colegiales que se elaboren, que podrán tener carácter interno (así sucede en el caso del CEMICAB). No obstante, hay algunos matices en este régimen eminentemente privado, entre los que destaca el hecho de que las personas que ejercen de mediadores son colegiados ejerciendo su actividad profesional y, por ello, quedan sometidos al régimen disciplinario del Colegio.

En cualquier caso, el Colegio no está prestando un servicio público, sino que, en última instancia, está defendiendo los intereses de sus colegiados, ya sea poniendo fin a las controversias surgidas entre ellos o con sus clientes, o bien facilitándoles un cauce para ejercer mejor su profesión cuando dicho ejercicio conlleve actuar como mediador.

b) La mediación pública. La condición de entidad mediadora que han adquirido los Colegios Profesionales permite que éstos administren la mediación a través de su propio servicio público de mediación.

En este caso, debe aplicarse de manera preceptiva el marco normativo de la mediación institucional contenido en las leyes y reglamentos de mediación, tanto estatales como autonómicos. La sumisión a dicho marco abarca, entre otras, las previsiones relativas a la formación que deben tener los mediadores; los trámites y duración que debe tener el procedimiento; el régimen disciplinario de los mediadores; o la retribución de la mediación.

La prestación de un servicio público conlleva la necesidad que el Colegio Profesional prestador del servicio de mediación deba situarse en su vertiente de ente público, actuando conforme a las reglas del Derecho Administrativo y respetando escrupulosamente las normas reguladoras del servicio público de mediación que, en última instancia, tienen como finalidad proteger a los usuarios del mismo.

\section{B. Materias sobre las que pueden mediar los Colegios Profesionales}

Tanto la legislación estatal como autonómica, en los términos que hemos visto en el apartado anterior, prevén que los Colegios Profesionales puedan organizar un servicio público de mediación, sin limitar el ámbito material de las mediaciones que se lleven a cabo en el mismo.

Atendiendo a lo anterior, en principio, el ámbito objetivo de los Servicios Públicos de mediación de los Colegios Profesionales abarca todas aquellas materias que la legislación reguladora de la mediación incluye en su ámbito de aplicación. 
$\mathrm{Al}$ respecto, el art. 2.1 Ley 5/2012 establece que la misma resulta de aplicación "a las mediaciones en asuntos civiles o mercantiles, incluidos los conflictos transfronterizos, siempre que no afecten a derechos y obligaciones que no estén a disposición de las partes en virtud de la legislación aplicable", ampliando así el ámbito material de la mediación institucional regulado en las normas autonómicas, en su inmensa mayoría circunscritas exclusivamente al ámbito familiar, con las únicas excepciones ya referidas de la Ley cántabra 1/2011 y la Ley Catalana 15/2009.

Además, el art. 2.2 Ley 5/2012 también delimita de manera negativa el ámbito de aplicación de la ley, excluyendo expresamente: la mediación penal, la mediación con las Administraciones públicas, la mediación laboral y la mediación en materia de consumo.

$\mathrm{Al}$ respecto, ya hemos visto que, en España, es en el marco del Derecho civil (primero en el ámbito familiar y después extendiéndose a otras materias) donde la mediación institucional se encuentra más desarrollada, siendo la única rama del Derecho que dispone de una normativa que regula la mediación con carácter general. Así, en relación a los ámbitos que quedan excluidos de la aplicación de la Ley 5/2012, aunque en los mismos se venga utilizando la mediación (junto con los demás medios alternativos de resolución de conflictos) desde hace años o incluso décadas ${ }^{49}$, no hay una norma específica que regule la mediación

49 Ya hemos apuntado que la primera normativa en España que reguló los sistemas alternativos de resolución de conflictos lo hacía en el ámbito laboral (Real Decreto Ley 5/1979, ya citado). Asimismo, este ámbito es el único en el que se exige obligatoriamente, para acudir a un proceso laboral, un intento de conciliación previa (art. 63 Ley de Procedimiento Laboral).

En los procesos civiles, antes de la reforma llevada a cabo en 1984, este intento de conciliación previa era presupuesto indispensable para poder plantear la demanda, pero ahora es facultativo.

Por su parte, en el ámbito administrativo, ya hace años que se reclama por parte de la doctrina un mayor uso de los medios de resolución alternativa de conflictos, que tanto descongestionarían la actividad de las Administraciones Públicas. Entre otras, pueden consultarse las obras de: Bustillo BoLAdo, R, Convenios y contratos administrativos: transacción, arbitraje y terminación convencional del procedimiento, Aranzadi, Pamplona, 2001; Carballo Martínez, G., La mediación administrativa y el Defensor del Pueblo, Thomson-Aranzadi, Navarra, 2008; Gamero Casado, E., Rodríguez Piñero-Royo, M.C. (Coords.), Mediación para la resolución de conflictos de personal en las administraciones públicas, Centro Andaluz de relaciones laborales, Sevilla 2006; Gamero Casado, E., "Estructura de la mediación en administraciones públicas: organización administrativa y procedimiento de mediación", en Gamero CaSAdo, E., Rodríguez PiÑero-Royo, M.C. (Coords.) (2006); GranAdo Hijelmo, I., "El arbitraje en derecho administrativo: algunas reflexiones sobre su fundamentación, Revista furídica Navarra, núm. 39, 2005; Loperena RoTA, D., La transacción en la nueva Ley de la jurisdicción contenciosa-administrativa, IVAP, Vitoria-Gasteiz, 2000; LóPez MenUdo, F., "Arbitraje y derecho público, Justicia Administrativa", Revista de Derecho Administrativo, núm. 2, 1999; MARESCa CAвот, J.C., "El arbitraje en la Ley de régimen jurídico de las Administraciones Públicas y del procedimiento administrativo común”, Revista del Tribunal Arbitral de Barcelona, Boletín núm. 7. 1994; MASUCCI, 
en dichos ámbitos, y, en cualquier caso, las referencias a la mediación contenidas en distintas normas sectoriales no prevén la intervención de los Colegios Profesionales como entidades mediadoras ${ }^{50}$, ni tampoco hay una práctica en este sentido.

Ordenadas así las cosas, y de acuerdo con el marco normativo actual vigente, los servicios públicos de mediación que pueden organizar los Colegios Profesionales quedan circunscritos al ámbito civil y mercantil.

No obstante lo anterior, hay otra cuestión relativa a las materias sobre las que pueden mediar los Colegios Profesionales que debemos abordar. La normativa relativa a la mediación permite, tal como acabamos de ver, que los Colegios Profesionales medien sobre todas las cuestiones que quedan dentro del ámbito de aplicación material de la Ley 5/2012, sin establecer que la mediación que desarrollen los Colegios Profesionales tenga que estar relacionada, de algún modo, con la actividad de los profesionales que estos agrupan.

Teniendo en cuenta lo anterior, y al menos desde un punto de vista teórico, un Colegio de Ingenieros Industriales podría desarrollar tareas mediadoras en relación a un divorcio o a una herencia; pudiendo también hacer lo propio un Colegio de Médicos en un conflicto derivado de los perjuicios patrimoniales producidos como consecuencia de la mala ejecución de un contrato de obras. Estas situaciones, aunque dentro de la legalidad, carecen de toda lógica, y resultan contrarias a la profesionalización y especialización de los mediadores que propugna la legislación de mediación estatal y autonómica.

\footnotetext{
A., "El procedimiento de mediación como medio alternativo de resolución de litigios en el Derecho administrativo: esbozo de las experiencias francesa, alemana e inglesa", RAP, núm. 178, 2009; PALOMAR OLmeda, A. en Gamero Casado, E., Rodríguez Piñero-Royo, M.C. (Coords.) (2006); Pérez Moreno, A., "Procedimientos de conciliación, mediación y arbitraje como alternativa a la vía administrativa de recurso", Revista Andaluza de Administración Pública, núm. 37, 2000; PÉrez Moreno, A., "Justicia administrativa y fórmulas alternativas" en La justicia administrativa: libro homenaje al profesor Dr. D. Rafael Entrena Cuesta (Montoro Chiner, M.J., Coord.), Atelier, 2003; Rosa Moreno, J., El arbitraje administrativo, MacGrawHill, Madrid, 1998; Sánchez Morón, M., Trayter Jiménez, J.M. y SÁnchez Blanco, A., La apertura del procedimiento administrativo a la negociación con los ciudadanos en la Ley 30/1992, de régimen juridico de las Administraciones Públicas y del Procedimiento Administrativo Común, Instituto Vasco de Administración Pública, Oñati, 1995; Tornos MAs, J., "Los medios alternativos de resolución de conflictos" en Derechos y garantías del ciudadano. Estudios en homenaje al Profesor Alfonso Pérez Moreno (Dir. LóPez Menudo, F.), Ed. Iustel, Madrid, 2011; Trayter Jiménez, J.M., "El arbitraje de Derecho administrativo", RAP, núm. 143, 1997; TraYTER Jiménez, J.M., "Materias susceptibles de mediación en conflictos individuales del personal de las Administraciones Públicas", en Gamero Casado, E., Rodríguez Piñero-Royo, M.C. (Coords.) (2006).

${ }^{50}$ Esta situación podría cambiar en el ámbito del Consumo en Cataluña, pues el Proyecto de Decreto sobre el procedimiento de mediación en las relaciones de consumo prevé en su art. 3 que los Colegios Profesionales tienen la consideración de organismos habilitados.
} 
Así, en nuestra opinión, cada Colegio Profesional, dentro del ámbito material amplio que contempla la ley, tiene que delimitar aquéllas concretas materias o tipos de conflictos que abarca su servicio público de mediación, siendo el instrumento idóneo para ello los Estatutos Colegiales o, en su caso, el eventual reglamento colegial que regule la prestación del servicio de mediación.

La especialización de los Colegios Profesionales en relación al tipo de conflicto, redundará en una mejor prestación del servicio público de mediación, lo cual tendría consecuencias positivas tanto para las partes como para los propios mediadores.

Por último, destacar que, cuando estemos ante un conflicto que verse sobre materias de distinta naturaleza, una posible solución para mantener el principio de especialización del mediador, es que intervengan distintos mediadores, posibilidad avalada por la Ley 5/2012, en su artículo 18. En estos casos, si los diversos mediadores que intervienen pertenecen a distintos Colegios Profesionales, éstos deberán prever mecanismos que garanticen los principios de colaboración y coordinación.

\section{Las personas mediadoras. Formación y mecanismos de control}

$\mathrm{Al}$ estudiar el marco normativo de la mediación, hemos podido comprobar que, entre los objetivos fijados por la nueva legislación, se encuentra el de profesionalizar la figura del mediador, previendo que el mismo tenga una especial formación y esté sometido a determinados mecanismos de control, lo que, en última instancia, redunda en una mayor calidad de la mediación institucional.

Tanto en lo referente a la formación del mediador como a los mecanismos de control sobre las personas mediadoras, tienen un papel destacado los Colegios Profesionales.

\section{A. La formación de las personas mediadoras}

La normativa estatal y autonómica coinciden (aunque en distintos términos) en exigir al mediador un "doble rasero de formación", exigiendo así, en primer lugar, una formación de carácter general de nivel superior; y, en segundo lugar, una formación específica para ejercer la mediación.

a) En cuanto a la formación de carácter general, el art. 11 de la Ley 5/2012 preveé que el mediador esté en posesión de un título oficial universitario o de formación profesional superior, sin exigir que dicho título esté circunscrito a una determinada área de conocimiento o disciplina. 
Atendiendo a lo anterior, entendemos que quedan sin efecto las previsiones de las distintas leyes autonómicas que, en el marco de la formación general del mediador, sólo admiten la titulación universitaria, y no la formación profesional superior $^{51}$; así como aquéllas que limitan dicha formación a determinados estudios ${ }^{52}$.

b) En cuanto a la formación específica para ejercer la mediación, el art. 11 Ley 5/2012, establece que la misma se adquirirá "mediante la realización de uno o varios cursos específicos impartidos por instituciones debidamente acreditadas, que tendrán validez para el ejercicio de la actividad mediadora en cualquier parte del territorio nacional".

El R.D.980/2013, concreta estas previsiones, exigiendo que la formación inicial tenta una duración mínima de 100 horas (art. 5) y la formación continua, al menos, 20 horas cada 5 años. En cuanto al los centros de mediación (art. 7). puden ser públicos o privados, siendo necesario que cuenten con una habilitación legal o autorización por la administración competente.

En la normativa de Cataluña, se dispone que los Colegios Profesionales (junto con los centros docentes universitarios y otras Corporaciones de Derecho Público) están acreditados para impartir la formación inicial homologada necesaria para adquirir la condición de mediador ${ }^{53}$, que deberá cumplir con los requisitos que prevé el art. 18 del Decreto 135/2012, concretados en la Orden JUS/428/2012, de 18 de diciembre.

En relación a la formación continuada, en Cataluña, los Colegios Profesionales también tienen reconocidas competencias de forma expresa en este ámbito

${ }^{51} \mathrm{La}$ admisión de los títulos profesionales de formación superior, y no sólo de los títulos universitarios, también resulta más conforme con el concepto de formación que esboza el Derecho Comunitario, previsto en la Directiva 2005/36/CE, de 7 de septiembre de 2005, relativa al reconocimiento de cualificaciones profesionales (art. 11). Este concepto amplio de cualificación también es el que recoge el art. 3 (Definiciones) del Anteproyecto de Ley de Servicios Profesionales de 2 de agosto de 2013.

${ }^{52}$ Así, por ejemplo, la Ley 1/2006, de 6 de abril, de Mediación Familiar de Castilla y León establece en su artículo 8 que para ejercer la mediación debe tenerse la titulación en Derecho, Psicología, Psicopedagogía, Sociología; Trabajo Social, Educación Social, y en cualquier otra Licenciatura o Diplomatura de carácter social, educativo, psicológico, jurídico o sanitario. En análogos términos se pronuncia el art. 8 de la Ley 4/2005, de 24 de mayo, del Servicio Social Especializado de Mediación Familiar de Castilla-La Mancha; y el art. 18 de la Ley 3/2007, de 23 de marzo, de Mediación Familiar de Asturias

53 Este requisito relativo a la formación homologada inicial de las personas mediadoras sólo puede excepcionarse en relación a aquellas personas que puedan adquirir la condición de mediador en atención a su experiencia y conocimientos. En cualquier caso, los requisitos y condiciones para inscribir en el Registro General de personas mediadoras a las personas que se encuentren en estas circunstancias tiene que realizarse por orden del Departamento competente en materia de Derecho civil, cosa que aún no se ha hecho. 
[art. 22 c) Ley 15/2009], estableciéndose los requisitos de la misma en los arts. 21 y 22 Decreto $135 / 2012^{54}$.

\section{B. Mecanismos de control sobre las personas mediadoras}

Los Colegios Profesionales también tienen reconocidas diversas funciones públicas en relación a los mecanismos de control a los que está sometido el mediador, y cuya finalidad es garantizar su profesionalidad y el cumplimiento de sus deberes. Entre dichos mecanismos de control, podemos distinguir:

\section{a. Vinculación a una institución de mediación}

Muchas de las normas autonómicas existentes en materia de mediación exigen que el mediador esté vinculado a alguna institución de mediación, vinculación que puede venir dada porque el mediador preste sus servicios en una Administración Pública, sea miembro de un Colegio Profesional o pertenezca a una Asociación Profesional (en Cataluña, art. 3 Ley 15/2009 y 17.2 Decreto 135/2012; en Aragón, art. 8.3 Ley 9/2011, de 24 de marzo; en Castilla-La Mancha, art. 6 Ley 4/2005, de 24 de mayo).

A nivel estatal, el art. 11 Ley 5/2012, al establecer las condiciones que deben reunir las personas que quieran ejercen como mediadores, no dice nada al respecto. En cualquier caso, debemos tener en cuenta que la colegiación de la persona mediadora sólo será obligatoria cuando así se derive de las normas reguladoras de su respectiva profesión, esto es, cuando sea un profesional sujeto a colegiación obligatoria ${ }^{55}$.

${ }^{54} \mathrm{El}$ art. 21 Decreto 135/2012 establece que las personas mediadoras deben realizar cursos para actualizar sus conocimientos que, como mínimo, deben suponer 40 horas bienales

Por su parte, el art. 22 Decreto 135/2012 establece que las personas mediadoras que incumplan con este deber, quedaran inactivas a los efectos de la posible derivación de mediaciones por parte del Centro de Mediación de Derecho Privado de Cataluña, pudiendo recuperar la condición de activas si acreditan una formación en mediación equivalente a 40 horas por cada 2 años sin formación acreditada. A partir de 3 años sin acreditación de la formación exigida, se podrá recuperar la condición de persona mediadora activa mediante la acreditación de formación especializada de un mínimo de 60 horas.

${ }^{55}$ En este ámbito, la futura Ley estatal de Servicios Profesionales introducirá importantes modificaciones, pues restringe significativamente aquellas profesiones sujetas a colegiación obligatoria. Al respecto, puede verse la Disposición Adicional Primera (Obligaciones de Colegiación) del Anteproyecto de Ley de Servicios Profesionales de 2 de agosto de 2013. 


\section{b. Deberes registrales de los mediadores}

El R.D. 980/2013, ha creado el registro mediadores y de instituciones de mediación, que dependerá del Ministerio de Justicia y que se coordinará con los registros de mediación autonómicos. La principal característica de este Registro es que, con la excepción de los mediadores concursales (art. 18), la inscripción tiene carácter voluntario (art. 11), lo que dificulta el adecuado cumplimiento de las finalidades del registro, esto es, la publicidad y la transparencia en materia de mediación.

Debemos destacar que, en este ámbito, la mayor parte de las Comunidades Autónomas ya han creado sus respectivos registros de mediadores, cuya finalidad es verificar el cumplimiento de los requisitos exigidos a los mediadores y facilitar la organización de la mediación institucional.

Las tareas asociadas a la llevanza de dichos registros se han distribuido entre las distintas entidades mediadoras, siendo especialmente destacadas las funciones encomendadas a los Colegios Profesionales, que en la mayoría de los casos efectúan las inscripciones de sus colegiados en el registro de mediadores, y se encargan también de la actualización de sus datos, en aquello que afecta a suspensiones, bajas, modificaciones y otros asientos ${ }^{56}$.

\section{c. Responsabilidad civil de los mediadores}

El art. 14 Ley 5/2012 establece que los mediadores "deben cumplir fielmente con su encargo, incurriendo, si no lo hicieren, en responsabilidad por los daños y perjuicios que causaren”. Para hacer frente a su eventual responsabilidad, el mediador debe suscribir un seguro o garantía equivalente que cubra la responsabilidad civil derivada de su actuación en los conflictos que intervenga (art. 11.3 Ley 5/2012), obligación que, en la regulación autonómica en materia de mediación familiar, únicamente se encontraba prevista en la Ley cántabra 1/2011.

A la hora de reclamar la responsabilidad, el perjudicado tiene acción directa contra el mediador; pero, además, también tiene una acción directa en relación con la institución de mediación (así, ante el Colegio Profesional), por los daños derivados de la designación del mediador o del incumplimiento de sus obligaciones como institución mediadora (art. 14 Ley 5/2012).

Sobre esta cuestión ha hecho especial hincapié el R.D. 980/2013, que confirma la responsabilidad solidaria de la institución de enseñanza por los daños constantes por la actuación del mediador (art. 26).

56 Así se prevé en Cataluña, arts. 5.6, 9.4 y 23.2 Decreto 135/2021; en Madrid, art. 6 Ley 1/2007; en Andalucía, art. 18.3 Ley 1/2009, de 27 de febrero; en Valencia, art. 12 Ley 7/2001, de 26 de noviembre. 


\section{d. Régimen sancionador de los mediadores}

La legislación estatal sólo ha regulado la responsabilidad civil, pero algunas normas autonómicas han regulado también un régimen sancionador para los mediadores ${ }^{57}$.

En este régimen sancionador, los Colegios Profesionales tienen reconocidas diversas competencias. Así, en relación a los mediadores colegiados, se prevé la competencia de los Colegios Profesionales para instruir los correspondientes procedimientos disciplinarios y, en su caso, imponer sanciones en las leyes de mediación de Madrid (arts. 20, 28 y 29 Ley 1/2007), la Comunidad Valenciana (arts. 25 y 29 Ley 7/2001), Castilla-La Mancha (art. 29 Ley 4/2005) y el País Vasco (art. 3.1 Ley 1/2008). Asimismo, en muchas otras leyes autonómicas se prevé que las eventuales sanciones que se impongan desde otras autoridades, sean comunicadas a los respectivos Colegios Profesionales (art. 31 Ley asturiana 3/2007; art. 20 Ley Canaria 15/2003).

Aunque la Ley 5/2012 no contenga, como hemos dicho, una previsión análoga a la de las legislaciones autonómicas, entendemos que la potestad disciplinaria que, con carácter general, tienen los Colegios Profesionales sobre sus colegiados [art. 5 i) LCP] así como su función de salvaguarda de la legalidad [art. 5 t) LCP] les habilita para ejercer la potestad disciplinaria cuando éstos cometan infracciones administrativas en su actuación como mediadores, sin que sea necesario que se prevea de forma expresa en la normativa de mediación. No obstante, en aras a la seguridad jurídica, ello sería, cuanto menos, recomendable.

\section{e. Códigos de conducta de los mediadores}

Todos estos mecanismos de control sobre los mediadores que acabamos de analizar se ven completados por una serie de mecanismos de soft law o autorregulación, esto es, códigos de conducta voluntarios a los que pueden adherirse tanto los mediadores como las instituciones de mediación (art. 12 Ley 5/2012).

Además de estos códigos, específicos de la mediación, cuando los mediadores pertenezcan a un Colegio Profesional, también deberán respetar, obviamente, los

\footnotetext{
${ }^{57}$ A modo de ejemplo, los arts. 31 a 33 de la Ley 15/2009, contienen un completo catálogo de infracciones y sanciones, previendo también los órganos sancionadores para cada caso. De forma supletoria al régimen previsto en la Ley 15/2009, se aplicarán las previsiones sobre la potestad sancionadora contenidas en el Decreto $278 / 1993$, de 9 de noviembre, sobre el procedimiento sancionador de aplicación a los ámbitos de competencia de la Generalidad, en aquello que no se oponga a la Ley 15/2009.
} 
códigos de conducta colegiales así como el conjunto de normas deontológicas de la profesión (entre otros, art. 34 Ley catalana 15/2009; art. 10 Ley aragonesa 9/2011; art. 33 Ley cántabra 1/2011).

\section{El procedimiento de mediación y el acuerdo de mediación}

A pesar de que la mediación se rige, con carácter general, por el principio antiformalista, en el ámbito de la mediación institucional, dicho principio debe ser matizado, pues aunque no se establece una regulación detallada del procedimiento de mediación estricto sensu, la ley sí prevé la realización de algunos trámite $^{58}$. A lo largo de este procedimiento, como veremos a continuación, la intervención de los Colegios Profesionales tiene un papel destacado.

\section{A. La solicitud de mediación y la designación de mediador}

Cuando las partes de un conflicto quieren someterse a mediación institucional, éstas formalizan su voluntad a través de una solicitud, que se formulará ante las instituciones de mediación (entre las que se encuentran los Colegios Profesionales) o directamente ante el mediador propuesto por una de las partes a las demás o designado de común acuerdo (art. 16.2 Ley 5/2012).

En el caso de que las partes no designen al mediador, dicha designación corresponderá realizarla a la institución de mediación, sin que la legislación estatal concrete cómo se deberá realizar la misma, aunque entendemos que se hará atendiendo a la materia sobre la que verse el conflicto y de acuerdo con un sistema de turno, tal como han hecho diversas Comunidades Autónomas. Así, en el caso de Cataluña, a falta de designación de mediador por las partes, se prevé que el mismo será designado por el Centro de Mediación de Derecho Privado de Cataluña, por un sistema de turno en función del ámbito de la mediación, la especialización y el partido judicial de las personas solicitantes (art. 28.4 Decreto 135/2012), siguiendo el procedimiento previsto en el art. 30 Decreto 135/2012.

Una vez formulada la solicitud, la institución de mediación o el mediador designado por las partes emplazarán a las mismas para la celebración de una sesión informativa, en la que se dará a conocer a las partes diversas circunstancias asociadas a la persona mediadora (experiencia, formación, posibles causas que puedan afectar su imparcialidad) y las características de la mediación (coste, organización del procedimiento, consecuencias jurídicas del acuerdo que eventual-

${ }^{58}$ Sobre las etapas de la mediación, Cavaldi, M.G y Quinteros Avellaneda, L.G. (2010): Págs. 107 y ss. 
mente se alcance).

\section{B. El desarrollo de la mediación}

Tras la sesión informativa, tiene lugar la sesión constitutiva (art. 19 Ley 5/2012), que da inicio propiamente al procedimiento de mediación ${ }^{59}$, y en la que las partes expresan su deseo de desarrollar la mediación y dejan constancia de diversos aspectos relacionadas con la misma, tales como la identificación de las partes sometidas a mediación, la designación de mediador y, en su caso, institución de mediación; el objeto del conflicto; el programa de actuaciones y duración máxima del procedimiento; el coste de la mediación o las bases para su determinación; el lugar de celebración y la lengua del procedimiento de mediación. De dicha sesión se levantará un acta en la que constarán todos los aspectos relatados y que será firmada por las partes y por el mediador, pudiéndose hacer constar también que la mediación se ha iniciado sin efecto.

El Decreto catalán 135/2012 también prevé el levantamiento del acta correspondiente a la reunión constitutiva o inicial, estableciendo además que la misma se tiene que hacer llegar al Centro de Mediación de Derecho Privado de Cataluña así como, en su caso, al Colegio Profesional al que pertenezca el mediador en un plazo de cinco días (art. 35).

En el caso de que la mediación sea administrada por el servicio público de mediación del Colegio, habrá dos cuestiones relativas al procedimiento que deberán tenerse en cuenta: la forma de desarrollo de la mediación y la duración de la misma.

${ }^{59}$ En cuanto al inicio de la mediación, el art. 16.3 establece que las partes podrán solicitar la suspensión de los procesos judiciales en curso de conformidad con lo dispuesto en la legislación procesal, recogiendo así la previsión del art. 770 LEC, introducida por la Ley 15/2005, de 8 de julio, de modificación del Código Civil y de la Ley de Enjuiciamiento civil en materia de separación y divorcio, que resolvió parcialmente uno de los problemas que tradicionalmente había planteado la mediación (y los demás métodos alternativos de resolución de conflictos) y es su posible uso en fraude de ley para lograr la prescripción de los plazos para ejercer acciones judiciales o la preclusión de los trámites en los procesos judiciales ya iniciados. Decimos que el problema se resolvió parcialmente porque queda aún pendiente de resolver qué sucede con aquellos procesos no iniciados, pero respecto a los cuales sí se han realizado diligencias preliminares o se han adoptado medidas cautelares. Resulta paradigmático el ámbito de las patentes, pues el art. 131.2 de la Ley de Patentes establece que "si en el plazo de dos meses a partir de la fecha de la práctica de las diligencias de comprobación no se hubiera presentado la correspondiente demanda ejercitando la acción judicial, quedarán aquellas sin efecto y no podrán ser utilizadas en ninguna acción judicial".

Al respecto, Pérez DAudí, V., "Aspectos procesales de la mediación en asuntos civiles y mercantiles", en Soleto Muñoz, H. (Dir.) (2011): págs. 385 y ss.; Martín Diz, F., La Mediación: sistema complementario de la Administración de Justicia, Consejo General del Poder Judicial, Madrid, 2010. Págs. 120 y ss. 
En lo relativo a la forma de desarrollo, aunque la mediación se ha caracterizado tradicionalmente por su presencialidad, este ámbito no escapa de la influencia que el uso de las TIC (Tecnologías de la Información y la Comunicación) está teniendo en la actuación de las Administraciones Públicas y la prestación de los servicios públicos. En este sentido, el art. 24 Ley 5/2012, prevé que las partes puedan acordar que "todas o alguna de las actuaciones de mediación, incluida la sesión constitutiva y las sucesivas que estimen convenientes, se lleven a cabo por medios electrónicos, por videoconferencia u otro medio análogo de transmisión de la voz o la imagen, siempre que quede garantizada la identidad de los intervinientes y el respeto a los principios de la mediación previstos en esta Ley". Asimismo, dispone el apartado segundo de este precepto, "La mediación que consista en una reclamación de cantidad que no exceda de 600 euros se desarrollará preferentemente por medios electrónicos, salvo que el empleo de éstos no sea posible para alguna de las partes".

Las previsiones anteriores han sido desarrolladas por el R.D. 980/2013, que en sus arts. 30 a 38 regula el determinado "procedimiento simplificado de mediación por medios electrónicos", cuya duración no excederá de un mes. La regulación reglamentaria de este procedimiento tiene como principal objetivo asegurar que se respetan todas las garantías necesarias.

En cuanto a la duración del procedimiento de mediación, la ley estatal sólo establece que el mismo será lo más breve posible, concentrándose también en el mínimo de sesiones posible (art. 20 Ley 5/2012), de acuerdo con la rapidez predicable de la mediación.

La regulación catalana resulta más detallada en este extremo, estableciendo que la mediación puede tener una duración máxima de 60 días, prorrogables motivadamente hasta treinta días más atendiendo a la complejidad del conflicto o partes implicadas en el mismo (art. 17 Ley 15/2009). Reglamentariamente, se ha establecido que el número máximo de sesiones es de seis en aquellos procedimientos de mediación en que intervengan hasta cuatro partes, siendo también prorrogables de manera motivada (art. 34.1 Decreto 135/2012).

\section{G. La terminación de la mediación}

Teniendo en cuenta el principio de voluntariedad que rige la mediación, las partes tienen derecho a desistir del procedimiento de mediación en cualquier momento, sin tener que agotar las sesiones previstas en el acta inicial. En este caso, lo comunicarán al mediador, que a su vez lo comunicará a las demás partes, produciéndose así la terminación anticipada del procedimiento. El mediador, a su 
vez, también puede renunciar a continuar en el procedimiento, pero ello no producirá la terminación del procedimiento, salvo que no se nombre un nuevo mediador (art. 22.2 Ley 5/2012).

Ya sea agotando las sesiones previstas o por terminación anticipada, el procedimiento de mediación puede concluir en un acuerdo entre las partes, o finalizar sin dicho acuerdo, pero en ambos casos se levantará un acta final del procedimiento que determinará la conclusión del mismo, reflejando los acuerdos alcanzados de forma clara y comprensible o su finalización por cualquier otra causa. El acta deberá ir firmada por el mediador, que se encargará de redactarla, y por las partes, entregándose un ejemplar a cada una de ellas. En el ámbito de Cataluña, se prevé que del acta final (art. 36 Decreto 135/2012) o de la finalización anticipada de la mediación (art. 37 Decreto 135/2012) se dé traslado al Centro de Mediación Privada de Cataluña, pero no al Colegio Profesional al que, eventualmente, pertenezca el mediador, tal como sucedía con el acta inicial. En nuestra opinión, tener conocimiento de que la mediación ha concluido y con qué resultado resulta tan trascendente, o incluso más, que tener constancia de su inicio, por lo que el trato diferencial entre el acta inicial y el acta final no encuentra justificación alguna.

Una vez finalizada la mediación por cualquiera de las vías que hemos visto, se devolverán los documentos a cada una de las partes; y, con los que no hubieran de devolverse, se formará una expediente que deberá custodiar el mediador o, en su caso, el Colegio Profesional (u otra institución de mediación que haya intervenido), por un plazo de cuatro meses.

\section{La retribución del mediador}

Una vez concluido el procedimiento, se debe llevar a cabo la retribución del mediador. La Ley 5/2012, no detalla cómo se llevará a cabo dicha retribución, cuestión que, previsiblemente, será objeto de regulación en su desarrollo reglamentario.

Por su parte, diversas Comunidades Autónomas ya han establecido algunas reglas al respecto. Muchas de ellas reconocen a los Colegios Profesionales una competencia para establecer normas orientadoras o, incluso en algunos casos, establecer directamente la retribución que corresponde a los mediadores (art. 8 Ley valenciana 7/2001; art. 15 Ley andaluza 1/2009; art. 9.2 Ley de Castilla-La Mancha 4/2005; art, 7 Ley canaria 15/2003).

En Cataluña, el art. 27 Ley 15/2009 establece que, con carácter general, la retribución se llevará a cabo por las partes en la mediación, reconociendo la po- 
sibilidad de que alguna de ellas (o ambas) pueda disfrutar del beneficio de gratuidad de la mediación, debiéndose cumplir para ello con los requisitos materiales previstos en las normas reguladoras de la asistencia jurídica gratuita. En este último caso, corresponderá al Centro de Mediación de Derecho Privado de Cataluña retribuir a las personas mediadoras la totalidad o la parte proporcional de la tarifa, lo cual hará a través de las entidades que colaboran con el Centro (art. 40 Decreto 135/2012), principalmente, los Colegios Profesionales.

\section{E. El acuerdo de mediación}

En el caso de que la mediación finalice con acuerdo entre las partes, el mismo podrá versar sobre la totalidad de las materias que se sometían a mediación o ser un acuerdo de carácter parcial.

El acuerdo de mediación debe distinguirse del acta final del procedimiento. Esta última, tal como hemos visto, recoge las diversas circunstancias de la conclusión de la mediación y los acuerdos adoptados, pero a grandes rasgos. Los aspectos de detalle de los pactos alcanzados se hacen constar en el acuerdo de mediación (art. 23 Ley 5/2012), un documento diferenciado en el que consta la identidad y domicilio de las partes, el lugar y fecha en que se suscribe, las obligaciones que cada parte asume y que se ha seguido un procedimiento de mediación ajustado a las previsiones de la ley, con indicación del mediador o mediadores que han intervenido y, en su caso, de la institución de mediación en la que se ha desarrollado el procedimiento. Este acuerdo de mediación deberá firmarse por las partes o sus representantes, y del mismo se entregará un ejemplar a cada una de ellas.

Finalmente, en relación al acuerdo de mediación, la Ley 5/2012 ha abordado dos cuestiones tradicionalmente conflictivas, esto es, su posible impugnación y su cumplimiento.

En relación a la impugnación, teniendo en cuenta que la mediación es un sistema de resolución de conflictos autocompositivo y regido, por tanto, por el principio de voluntariedad, el eventual acuerdo que se alcance no deja de ser un acuerdo de voluntades y, por ello, el art. 23.4 Ley 5/2012 prevé que la única manera de impugnar su contenido sea a través de la acción de nulidad por las causas que invalidan los contratos (art. 1261 Código civil). En cuanto al plazo para interponer la acción de nulidad contra el acuerdo de mediación, resultarán de aplicación las reglas contenidas en el art. 1301 Código civil.

En cuanto al cumplimiento del acuerdo de mediación, el mismo tiene per se carácter vinculante para las partes; pero, además, y en aras a perseguir una mayor seguridad jurídica, el art. 25 Ley 5/2012 prevé que el acuerdo de mediación pueda 
adquirir la naturaleza de título ejecutivo a través de dos vías. La primera de ellas, se concreta en la elevación del acuerdo de mediación a escritura pública ante un notario, que realizará previamente un control de legalidad respecto a los trámites que se han seguido en el procedimiento de mediación así como en relación al contenido del acuerdo. En este caso, el tribunal competente para la ejecución será el Juzgado de Primera Instancia del lugar en que se hubiera firmado el acuerdo (art. 26 Ley 5/2012). La segunda vía es la homologación judicial del acuerdo, en los términos previstos en la LEC, cuando la mediación se haya desarrollado después de iniciarse un procedimiento judicial, siendo este mismo tribunal el competente para ejecutar el acuerdo homologado (art. 26 in fine Ley 5/2012).

Adicionalmente, debemos tener en cuenta que la Ley 5/2012 también resulta de aplicación a conflictos transfronterizos, por lo que, en estos supuestos, la formalización del título ejecutivo así como la ejecución del acuerdo se regirá por unas reglas específicas (art. 25.3 y 37 Ley 5/2012).

En cualquier caso, la conversión del acuerdo de mediación en un título ejecutivo queda fuera del procedimiento de mediación en sentido estricto, tal como demuestra el hecho de que, ni en un caso ni en otra, sea necesaria la presencia o intervención del mediador o de la institución de mediación.

\section{Funciones relacionadas con el desarrollo e impulso de la me- diación institucional}

Además de las funciones concretas que desarrollan los Colegios Profesionales en relación a las personas mediadoras, así como en el propio procedimiento de mediación, tanto el legislador estatal como autonómico han querido reconocer a los Colegios Profesionales una función general de impulso y desarrollo de la mediación.

En este sentido, el art. 17.2 Ley 5/2012 prevé que los Colegios Profesionales (comprendidos entre las instituciones de mediación) celebren sesiones informativas de carácter general para aquellas personas que pudieran estar interesadas en acudir a la mediación (art. 17.2 Ley 5/2012).

La legislación autonómica de mediación, una vez más, resulta más detallada que la Ley 5/2012. En particular, el art. 17 de la Ley cántabra 1/2011 y el art. 22 de la Ley catalana 15/2009 están dedicados a concretar las tareas que desempeñan los Colegios Profesionales como entidades mediadoras. Entre éstas, además de aquéllas a las que ya hemos hecho referencia a lo largo de este estudio, se encuentran la elaboración de propuestas y emisión de informes en relación a procedimientos de mediación; o la elaboración de una memoria anual de las actividades del Colegio Profesional en el ámbito de la mediación [art. 22 i) y j) Ley 15/2009] ${ }^{60}$. 
Finalmente, diversas normas autonómicas de mediación prevén la participación de los Colegios Profesionales en los respectivos órganos autonómicos creados para impulsar y difundir la mediación. Así, en Cataluña, el Comité asesor (art. 24 Ley 15/2009) está formado por representantes de los Colegios Profesionales, de las asociaciones representativas de entes locales y de otras asociaciones y por expertos con experiencia en el campo de la mediación, y tiene encomendadas, entre otras funciones: proponer acciones de divulgación de la mediación, informar sobre los códigos deontológicos y protocolos de buenas prácticas, proponer y favorecer la realización de estudios y evaluaciones globales de la mediación. También tienen órganos análogos, que cuentan con la participación de los Colegios Profesionales, las Comunidades de Madrid (Comisión Autonómica de Mediación Familiar, art. 7 Ley 1/2007); el País Vasco (Consejo Asesor de la Mediación Familiar; art. 11 Ley 1/2008, de 8 de febrero); o Cantabria (Observatorio de Mediación de la Comunidad Autónoma de Cantabria, art. 18 Ley 1/2011, de 28 de marzo).

\section{GONSIDERACIONES FINALES}

${ }^{60}$ La redacción completa del art. 22 Ley 15/2009 es la siguiente:

"Los colegios que integran a los profesionales que hacen mediaciones en el ámbito de la presente ley ejercen las siguientes funciones:

a) Gestionar el registro de personas mediadoras que estén colegiadas y comunicar las altas y bajas al Centro de Mediación de Derecho Privado de Cataluña".

b) Proponer al Gentro de Mediación de Derecho Privado de Cataluña la persona mediadora cuando las partes se dirijan colegio profesional.

c) Llevar a cabo la formación específica y declarar la capacitación de las personas mediadoras.

d) Cumplir la función deontológica y disciplinaria respecto a los colegiados que ejercen la mediación.

e) Comunicar al Centro de Mediación de Derecho Privado de Cataluña las medidas adoptadas como consecuencia de los expedientes disciplinarios abiertos a personas mediadoras.

f) Colaborar con el Centro de Mediación de Derecho Privado de Cataluña en el fomento y difusión de la mediación.

g) Introducir, en el ámbito de la formación especializada que lleven a cabo, el estudio de las técnicas de mediación, negociación y resolución alternativa de conflictos.

h) Elaborar propuestas y emitir los informes sobre los procedimientos de mediación que le pida el Centro de Mediación de Derecho Privado de Cataluña.

i) Elaborar una memoria anual de las actividades del colegio profesional en el ámbito de la mediación, que debe enviarse al Centro de Mediación de Derecho Privado de Cataluña.

j) Llevar a cabo formación de capacitación en materia de violencia en el ámbito familiar, para detectar e identificar situaciones de riesgo, prestando una especial atención a las que afecten a personas en situación de dependencia." 
Como destacábamos al inicio de este trabajo, los Colegios Profesionales han asistido en los últimos tiempos a una reformulación de sus fundamentos, una alteración de sus funciones y una transformación de su régimen jurídico, cambios que han llevado, incluso, a cuestionar su razón de ser, poniendo en peligro el lugar preeminente que tradicionalmente han ocupado estas corporaciones en el marco de la actividad pública.

En este contexto, una nueva corriente legislativa ha hecho que estas corporaciones adquieran un papel protagonista en la mediación institucional en el ámbito civil y mercantil, una de las instituciones que, como hemos podido comprobar, está acaparando la atención del legislador estatal y autonómico, y que se presenta como una de las grandes soluciones a los problemas de los que adolece la Administración de Justicia en el momento actual.

La configuración de los Colegios Profesionales como entidades mediadoras en el marco de la mediación institucional, conlleva que estos se erijan como prestadores del servicio público de mediación; pero, además, y lo que es aún más importante, que se les reconozcan importantes funciones públicas vinculadas al desarrollo e implantación de la mediación institucional, tales como la formación de las personas mediadoras, el ejercicio de potestades de control y disciplinarias sobre las mismas, o su participación en las iniciativas y organismos públicos relacionadas con esta institución.

La legislación estatal de mediación (pendiente de desarrollo reglamentario), al reconocer la condición de institución de mediación de los Colegios Profesionales, lo hace partiendo de mínimos, estableciendo únicamente que todos los Colegios Profesionales tienen entre sus funciones el impulso y desarrollo de la mediación, dejando en manos de cada uno de ellos que éstos asuman más o menos competencias dentro del abanico de posibilidades que les brindan las distintas legislaciones autonómicas.

Con este telón de fondo, estando aún recientes las huellas de la transposición de la Directiva Servicios y a la espera de las consecuencias que tendrá la futura Ley de Servicios Profesionales, sólo el tiempo dirá si la condición de institución de mediación de los Colegios Profesionales acabará por convertirse en uno de los elementos principales en la actividad de estas Corporaciones. 


\section{BIBLIOGRAFÍA}

AAVV (Coord. Martín-Retortillo, L.), Los Colegios Profesionales a la luz de la Constitución, Ed. Civitas, Madrid, 1996.

AA.VV. Retos y oportunidades para la transposición de la Directiva de Servicios (2009), 25 edición del Libro Marrón, Círculo de Empresarios, Madrid.

AA.VV., "El impacto de la Directiva Bolkestein y la reforma de los servicios en el Derecho Administrativo" (Dir. E. Moreu Carbonell), Monografías de la Revista Aragonesa de Administración Pública, Zaragoza, 2010.

AA.VV., Retos de la Directiva de Servicios, Revista Catalana de Dret Públic nº42, in totum (Dir. B. Noguera y S. SARTORIO), 2010.

AAVV., La mediación en tiempos de incertidumbre (Dir. Morente MejÍAs, F.), Ed. Dykinson, Madrid, 2010.

AAVV. El impacto de la Directiva de Servicios en las Administraciones Públicas: aspectos generales y sectoriales (Dir. Aguado i Gudolà, V. y Noguera de la Muela, B.), Atelier, 2012;

AAVV. La termita Bolkestein (Dir. Alba Nogueira), Dykinson, 2012.

AAVV, Duplà MARÍn, MTT. (Coord.), El régimen jurídico de la mediación familiar en España. Análisis de la normativa autonómica, Ed. Andavira, Santiago de Compostela, 2012.

AaVV (Dir. C. Fernández Canales; Coord. M. Blanco Carrasco), Mediación en asuntos civiles y mercantiles: comentarios a la Ley 5/2012; Madrid: Reus, 2012.

Baena de Alcázar, M. Los Colegios Profesionales en el Derecho Administrativo Español, Ed. Montecorvo, Madrid, 1968.

Barona VILAR, S., Mediación en asuntos civiles y mercantiles en España: tras la aprobación de la Ley 5/2012, de 6 de julio, de mediación en asuntos civiles y mercantiles, Tirant lo Blanch, Valencia, 2013.

Bush, R.B., Folger, J., The promise of mediation, San Francisco: Jossey Bass (New and revised edition), 2005.

Bustillo Bolado, R, Convenios y contratos administrativos: transacción, arbitraje y terminación convencional del procedimiento, Aranzadi, Pamplona, 2001.

ButTs Griggs, Respuestas al cuestionario del CEJ sobre mediación, Madrid, 2008.

Calvo Sánchez, L. Régimen jurídico de los Colegios Profesionales, Ed. Civitas, Madrid, 2000.

Carballo Martínez, G., La mediación administrativa y el Defensor del Pueblo, Thomson-Aranzadi, Navarra, 2008.

Carlón Ruiz, M., "El impacto de la Transposición de la Directiva de Servicios en el régimen jurídico de los Colegios Profesionales", RAP núm. 183, 2010.

Cavalli, M.G y Quinteros Avellaneda, L.G, Introducción a la gestión no adversarial de conflictos. Instituto Complutense de Mediación y Resolución de Conflictos, Madrid, 2010. 
De la Guadra Salcedo Janini, T. “¿Quo Vadis, Bolkestein? ¿Armonización o desregulación?", Revista Española de Derecho Europeo n 22, Madrid, 2007.

De la Guadra Salcedo, T. El mercado interior de servicios en la Unión Europea. Estudios sobre la Directiva 123/2006/CE relativa a los servicios en el mercado interior. Ed. Marcial Pons, Madrid, 2009.

Del Saz Cordero, S. "La modificación de la Ley estatal 2/1974, de colegios profesionales, como consecuencia de la transposición de la Directiva de servicios", Revista catalana de dret públic, Núm. 42, junio 2011.

FABIANI, M., "Profili critici del rapporto fra mediaciones e proceso", en fudicium (en línea:

http://www.judicium.it/admin/saggi/98/Fabiani.mediazone.pdf). Faget, "La doublé vie de la médiation", Droit et Societé, 29, 1995.

Fuertes López, M., "Luces y sombras en la incorporación de la Directiva de Servicios", RCDP n42, pp. 57-83, 2011.

Galeote Muñoz, M. "La necesidad de un método profesional de mediación: la importancia de la intervención del abogado en este proceso", IW Working Paper Derecho, 15 de abril de 2005.

Gamero Casado, E., Rodríguez Piñero-Royo, M.C. (Coords.), Mediación para la resolución de conflictos de personal en las administraciones públicas, Centro Andaluz de relaciones laborales, Sevilla 2006.

García López, P.A., "Transposición de la Directiva de Servicios en el caso de España", Partida Doble núm. 195, 2008.

González-Cuéllar Serrano, N. y Penín Alegre, M.L, "Mediación: una aproximación desde el derecho y la psicología" en Mediación: un método de? de conflictos. Estudio interdisciplinar (Coords. SAnz Hermida, Á. Ma y Ortiz PraDILlo, J.C.), Ed. Colex, Madrid, 2010.

González García, J., "La transposición de la Directiva de Servicios: Aspectos normativos y organizativos en el Derecho español", Revista Española de Derecho Europeo, núm. 32, 2009.

Granado Hyjelmo, I., "El arbitraje en derecho administrativo: algunas reflexiones sobre su fundamentación, Revista Furídica Navarra, núm. 39, 2005.

Laguna de Paz, J.C., "La Directiva de Servicios: El estruendo del parto de los montes", El Cronista del Estado Social y Democrático de Derecho, núm. 6, 2009.

Loperena Rota, D., La transacción en la nueva Ley de la jurisdicción contenciosa-administrativa, IVAP, Vitoria-Gasteiz, 2000.

López Menudo, F., "Arbitraje y derecho público, Justicia Administrativa", Revista de Derecho Administrativo, núm. 2, 1999.

Maresca Cabot, J.C., "El arbitraje en la Ley de régimen jurídico de las Administraciones Públicas y del procedimiento administrativo común", Revista del Tribunal Arbitral de Barcelona, Boletín núm. 7. 1994. 
Martín Diz, F., La Mediación: sistema complementario de la Administración de fusticia, Consejo General del Poder Judicial, Madrid, 2010.

Martínez LóPez-Muñiz, J.L., "Naturaleza de las Corporaciones Públicas Profesionales", Revista Española de la Administración Pública, Civitas, núm. 39, 1983.

MAsucci, A., "El procedimiento de mediación como medio alternativo de resolución de litigios en el Derecho administrativo: esbozo de las experiencias francesa, alemana e inglesa", RAP, núm. 178, 2009.

Muñoz Machado, S. y Fernández, T.R. (2008). "La Directiva Bolkestein: Liberalización al servicio del consumidor", Asociación para el Progreso de la Dirección, núm. 231, 2008.

Pérez Moreno, A., "Procedimientos de conciliación, mediación y arbitraje como alternativa a la vía administrativa de recurso", Revista Andaluza de Administración Pública, núm. 37, 2000.

Pérez Moreno, A., "Justicia administrativa y fórmulas alternativas" en La justicia administrativa: libro homenaje al profesor Dr. D. Rafael Entrena Cuesta (MONTORO Chiner, M.J., Coord.), Atelier, 2003.

Parejo Alfonso, L., "La desregulación de los servicios con motivo de la Directiva Bolkestein: La interiorización, con paraguas y en ómnibus de su impacto en nuestro sistema”. El cronista del Estado Social y Democrático de Derecho, junio 2009.

Petit, F., Auvergnon, P., Gil y Gil, J.L., Cruz Villalón, J., Trudeau G., VeiLLEUX, D., Le règlement amiable des différends sociaux, Étude juridique: France, Espagne, Québec, L’Harmattan, Paris, 2007.

Poblet, M., Courts and mediation. New paths for justice, European Presss Academic Publishing, Firenze, 2011.

Redorta, J., "La justicia del futuro", en Simposio sobre Tribunales y Mediación. Nuevos caminos para la fusticia. Comunicaciones. Ed. Gemme, Barcelona 2009.

Rosa Moreno, J., El arbitraje administrativo, MacGraw-Hill, Madrid, 1998.

Rivero Ortega, R. (Dir.), Mercado Europeo y reformas administrativas. La transposición de la Directiva de Servicios en España, Givitas-Thomson Reuters, Cizur Menor, 2009.

Rivero Ortega, R., "Antecedentes, principios generales y repercusiones administrativas de la Directiva de Servicios: Problemas de su transposición en España", Revista de Estudios Locales, número monográfico, 2009.

Salom Parets, A., Los Colegios Profesionales, Ed. Atelier, Barcelona, 2007.

Sánchez Morón, M., TraYter Jiménez, J.M. y Sánchez Blanco, A., La apertura del procedimiento administrativo a la negociación con los ciudadanos en la Ley 30/1992, de régimen jurídico de las Administraciones Públicas y del Procedimiento Administrativo Común, Instituto Vasco de Administración Pública, Oñati, 1995.

Scarselli, G., "La nuova mediazione e conciliazione: le cose che non vanno", en Fudicium (en línea: http://www.judicium.it/adminsaggi/46/scarsell.pdf).

Soleto Muñoz, H. (Dir.), Mediación y resolución de conflictos: técnicas y ámbitos, Ed. 
Tecnos, Madrid, 2011.

Tornos Mas, J., "Los medios alternativos de resolución de conflictos" en Derechos y garantías del ciudadano. Estudios en homenaje al Profesor Alfonso Pérez Moreno (Dir. López Menudo, F.), Ed. Iustel, Madrid, 2011.

Trayter JiméNeZ, J.M., "El arbitraje de Derecho administrativo", RAP, núm. 143, 1997.

Trayter Jiménez, J.M., "Presente y futuro de los colegios profesionales, en Aguado Gudolà V. y Noguera de la Muela B. (Dirs.), El impactode la Directiva de Servicios en las Administraciones Públicas: aspectos generales y sectoriales, Atelier, Barcelona 2012.

Vicente Ruiz, Mª D., "La reforma de la Ley de Colegios Profesionales impulsada por la Directiva de Servicios", Boletín Económico de Información Comercial Española núm. 2990, 2010.

Viola Demestre, I., "La mediación en asuntos civiles y mercantiles (breves notas a la Ley 5/2012, de 6 de julio)", en Revista Chilena de Derecho y Ciencia Política, Agosto-Diciembre 2012.

Villarejo Gallende, H., Salvador Armendáriz, M.A. "El complejo proceso de transposición de la Directiva de Servicios", en Informe de Comunidades Autónomas 2008, vol. I, Ed. Instituto de Derecho Público, Barcelona, 2009. 